\title{
El espejismo de la institucionalización: evolución del sistema de partidos en Venezuela (1958-1998)
}

\author{
The mirage of instritutionalization: \\ evolution of the party system in Venezuela
}

Andrés Dockendorff V*

\section{Resumen}

Como se examina en el artículo, el colapso del sistema partidista venezolano se incubó en el marco de un sistema de partidos hiperinstitucionalizado, caracterizado por bajos niveles de incertidumbre, ciudadanos indiferentes, un mercado político clausurado, baja credibilidad de los liderazgos partidistas y un antipartidismo latente. Como se discute, la perspectiva de la institucionalización del sistema de partidos propuesta por Mainwaring y Scully (1995) resulta insuficiente para analizar a los sistemas hiperinstitucionalizados. Estos producen dinámicas sistémicas que exceden el continuo y los criterios empleados por el enfoque de la institucionalización. En este caso, los altos niveles de estabilidad electoral se anclaron no tanto en la capacidad adaptativa y la competitividad de los partidos que componían el sistema, sino en la existencia de un mercado político cerrado y una institucionalidad electoral que fabricó

Profesor Investigador de la Academia Nacional de Estudios Políticos y Estratégicos (ANEPE) e Investigador Asociado del Instituto de Asuntos Públicos, Universidad de Chile. dockendorf@gmail.com.

Recibido el 8 de septiembre de 2009; aceptado el 3 de mayo de 2010. 
estabilidad y facilitó el predominio de los viejos partidos, la AD y el COPEI. El caso venezolano proporciona pistas para el estudio de otros sistemas de partidos donde los indicadores convencionales arrojan altos niveles de institucionalización, como Chile, Costa Rica y Uruguay.

Palabras clave: Sistema de partidos - hiperinstitucionalización - Venezuela

\section{Abstract}

This paper examines the collapse of the Venezuelan party system within the frame of a hyperinstitutionalized system characterized by low levels of uncertainty, the indifference of citizens, a closed political market, low credibility of party leadership and latent anti-party feelings. It is argued that institutionalization of party systems as proposed by Mainwaring and Scully (1995) is insufficient to analyze hyperinstitutionalized systems, for they produce systemic dynamics that go beyond the continuum and criteria used by the institutionalization approach. En this case, high levels of electoral stability were rooted not so much in the parties' capacity to adjust themselves but rather in the existence of a closed political market and an electoral institutionality that generated stability and facilitated the dominance of old parties, AD and COPEI. The Venezuelan case provides clues for the study of other party systems where traditional indicators show high levels of institutionalization, such as Chile, Costa Rica and Uruguay.

KEY wORDS: party system, hyperinstitutionalization, Venezuela. 
ANDrés DockendorfF • El espejismo de la institución...

\section{INTRODUCCIÓN}

Un sistema partidista corresponde al encuadre de interacciones que caracterizan la competencia entre los partidos, lo que presume cierta continuidad de los actores respeto de las reglas del juego y la efectividad de los partidos en dar cuerpo a la competencia electoral a través de sus símbolos y programas (Mainwaring y Scully, 1995; Malamud, 2003; Mainwaring y Torcal, 2005). Un sistema de partidos puede entenderse como un «fenómeno multidimensional» (Bardi y Mair, 2008), que da cuenta de la composición estructural de los partidos en un sistema político (Nohlen, 1995: 38). Su importancia estriba en el hecho de que refleja el juego político de una sociedad, ya que en torno al sistema partidista convergen las principales fuerzas políticas y todo aquello relevante desde el punto de vista político (Alcántara, 2004; Nohlen, 1995).

El trabajo de Mainwaring y Scully (1995) situó la institucionalización de los sistemas partidistas en el centro de la agenda de investigación y sus criterios fueron adoptados en un sinnúmero de trabajos comparados y estudios de caso $^{1}$. Los autores definieron un sistema de partidos institucionalizado ${ }^{2}$ como

1 Sobre el empleo por numerosos estudiosos de la definición y el enfoque de Mainwaring y Scully, ver Rodríguez (2007).

2 Mainwaring y Scully siguen la definición de institucionalización proporcionada por Samuel Huntington, para quien esta corresponde al "proceso a través del cual las organizaciones y procedimientos adquie- aquel donde los partidos se afianzan y se dan a conocer, y los actores; "desarrollan expectativas, orientaciones y conductas basándose en la premisa de que esa práctica u organización prevalecerá en el futuro» (p. 4). Un sistema de partidos institucionalizado cumple con los siguientes criterios o condiciones:

1. Regularidad y estabilidad de las pautas de competencia entre los partidos.

2. Los partidos más importantes tienen raíces fuertes en la sociedad.

3. Los actores relevantes del sistema político reconocen la legitimidad de los procesos electorales y los partidos como único medio para acceder al poder

4. Los partidos no están supeditados a los intereses de liderazgos personalistas o caudillos, poseen una firme implantación territorial y cuentan con estatutos y procedimientos respetados (Mainwaring y Scully, 1995: 4-5).

La institucionalización de un sistema partidista reflejaría, entre otras cosas, el funcionamiento global del sistema político, la legitimidad de los gobiernos y la calidad de la representación (Coppedge, 1998; Del Campo y Ramos, 1999). Los países que cuentan con sistemas de partidos institucionalizados ven facilitada la gobernabilidad, ya que procesan mejor el conflicto

ren valor y estabilidad» (Hungtinton, 1990: 23). 
político, los vínculos entre el gobierno y la legislatura son más fuertes, las políticas son más coherentes y los acuerdos perduran en el tiempo (Levitsky y Cameron, 2003; Mainwaring y Torcal, 2005; Stein et al., 2006; Stein y Tommasi, 2006; Mainwaring y Scully, 2008).

En general, en los sistemas partidistas institucionalizados, los partidos estructuran el proceso político. En cambio, en aquellos sistemas menos institucionalizados, los partidos no dan forma al proceso político, los niveles de incertidumbre e improvisación son más altos, la política se vuelve más errática, la legitimidad y la gobernabilidad se ven negativamente afectadas, no se desarrollan controles y equilibrios institucionales y predominan prácticas patrimoniales (Mainwaring y Scully, 1995:18).

En este trabajo se examina la evolución del sistema de partidos venezolano entre 1958 y 1998. El artículo se organiza de la siguiente forma. En una primera parte se describen los orígenes y las características generales del sistema de partidos surgido en la primera mitad del siglo XX, dando cuenta la estructura bipartidista reflejada en la composición del congreso y la rotación continua en el ejecutivo de los dos partidos predominantes en este período. En la segunda sección se analizan los factores que incidieron en el colapso del sistema de partidos venezolano, revisando la evolución de la volatilidad electoral, el número efectivo de partidos (NEP), los incentivos y efectos asociados al sistema electoral, el abstencionismo y datos sobre las actitudes políticas de los venezolanos. Posteriormente, se exponen algunas explicaciones alternativas relativas al colapso del sistema de partidos venezolano. De lo anterior se concluye que la baja capacidad adaptativa de los partidos fue erosionando la representatividad y legitimidad del sistema, mientras que, por otro lado, el bajo rendimiento gubernamental aceleró el descrédito de los mismos partidos y el sistema en su conjunto.

Como se discute en el trabajo, la perspectiva de la institucionalización del sistema de partidos resulta parcialmente útil para reconstruir analíticamente el sistema partidista en términos de su estabilidad y fragmentación. No obstante, el concepto y los criterios que se emplean en su medición son insuficientes para capturar cierto tipo de transformación a nivel sistémico: la hiperinstitucionalización. El estudio de la institucionalización condujo a un espejismo analítico, derivado de la fuerza individual de un reducido número de partidos y de la penetración, por parte de esos partidos, de los espacios organizativos de la sociedad civil y las instancias de representación corporativa. Este espejismo también se explica al dejar fuera del análisis la institucionalidad electoral, que en este caso parece haber generado niveles de estabilidad y fortaleza artificiales.

El estudio del proceso y las condiciones que delimitaron el colapso del sistema partidista venezolano proporciona varias lecciones para el estudio comparado de otros sistemas partidis- 
Andrés DockendorfF • El espejismo de la institución...

tas definidos convencionalmente como altamente institucionalizados, entre los que se cuentan Costa Rica, Uruguay y Chile. ¿Qué síntomas prefiguran la descomposición y el colapso de un sistema de partidos estable e institucionalizado? ¿Qué elementos caracterizan a un sistema de partidos hiperinstitucionalizado? $¿$ Qué variables deben incluirse en el estudio de sistemas de partidos fuertes e institucionalizados?

\section{ORÍGENES Y FISONOMÍA DEL SISTEMA PARTIDISTA VENEZOLANO}

Frente a sus pares europeos, en América Latina los sistemas de partidos latinoamericanos han sido marcadamente «discontinuos», en tanto poseen bajos niveles de estructuración y se han visto aquejados por una crónica inestabilidad y fuertes dosis de personalismo (Dix, 1989). En el caso venezolano, el caudillismo fue una característica fundamental del proceso político hasta mediados del siglo XX. Mientras tanto, los partidos fueron irrelevantes -y casi inexistentes- hasta la década de 1940 (Alexander, 1965; Martz, 1992). Por ello, el rol de los partidos está ligado indisolublemente a la instauración de la democracia, la que luego de algunos tropiezos iniciales se estableció definitivamente en $1958^{3}$. La prosperidad

Smith (2004) clasifica a Venezuela como país «no democrático» entre 1900-1945, «democrático» en el período 1946-1948, y nuevamente «no democrático» entre democrática de casi medio siglo estuvo correlacionada positivamente con las condiciones económicas del país (Mainwaring, 1999), donde el petróleo jugó un rol único y fundamental en la formación y mantención del sistema político y el ordenamiento de los partidos (Karl, 1987; Levine y Crisp, 1999).

Luego de una etapa de emergencia de los partidos, (1946-1948), caracterizada por mayores grados de intransigencia y conflictividad, a fines de la década de 1950 la actitud de los actores sufrió una notable transformación que permitió la instauración de una democracia partidista dotada de altos niveles de consenso y cooperación (Martz, 1992; Mc Coy y Smith, 1995; Molina y Pérez, 1998a $)^{4}$, y que se cristalizó en el Pacto de Punto Fijo (1958), promovido por los líderes de Acción Democrática (AD), del Comité de Organización Político Electoral Independiente (COPEI) y de la Unión Republicana Democrática (URD $)^{5}$. Este macro-acuerdo representó

1949 y 1957. Finalmente, en el período que aquí se examina, 1958 a 1998, se considera a Venezuela como país «democrático». La democratización venezolana se inscribiría temporalmente en lo que Huntington (1994) fijó como la «segunda ola de democratización» desde 1943 a 1962, resistiendo la «segunda contraola» de 1958 a 1975.

4 Al igual que la mayoría de los países de América Latina, Venezuela ha enfrentado la tensión entre democracia y gobernabilidad, y la compleja combinación entre presidencialismo y multipartidismo (Hartlyn, 1998; Chasquetti, 2001).

5 El Partido Comunista Venezolano (PCV) fue excluido de este macro-acuerdo. 
un punto de inflexión en la configuración de la institucionalidad democrática y el sistema de partidos, estableciendo las pautas y restricciones que delinearon el proceso político durante casi cuatro décadas ${ }^{6}$. El consenso y la lógica cooperativa que permearon el sistema político y partidista fueron formalizados a través de una carta fundamental ad hoc, que instauró un ordenamiento constitucional tendiente a generar un sistema político dotado de viabilidad intertemporal (Kornblith, 1991). Además, ensambló un presidencialismo amortiguado por un fuerte balance y contrapeso entre el poder ejecutivo y el legislativo (Brewer, 2008). En este equilibrio, los partidos cumplían un rol fundamental.

La fortaleza, la competitividad y el alto grado de vinculación con la sociedad de los partidos venezolanos es considerado como un aspecto central en la exitosa democratización del país (Corrales, 2001). El primer partido político en aparecer en el país fue la $\mathrm{AD}$, convirtiéndose en el vehículo de desarrollo político y social más importante $^{7}$. Los democratacristianos se

6 El acuerdo estableció las bases de la gobernabilidad democrática, el respeto a los resultados electorales, el acuerdo y el consenso como bases del sistema a través de la fijación de un Programa Gubernamental Mínimo, el respeto a la Constitución y un gobierno de unidad nacional (García, 2006).

7 A mediados de la década de 1940, la AD llegó al poder de la mano de jóvenes militares disconformes. En esta época los partidos se multiplicaron paralelamente a organizaron en el COPEI, partido que combinaba elementos conservadores y social-cristianos ${ }^{8}$. El tercer partido importante en surgir en esa época fue la URD, formada por partidarios del General Medina Anguita y opositores de la AD. Los comunistas, ya existentes previamente, se dividieron en dos partidos: el Partido Comunista de Venezuela (PCV) y el Partido Revolucionario Proletario?.

Michael Coppedge (1997) clasifica los partidos políticos de 11 países de América Latina que obtienen votos en las elecciones de la Cámara Baja, encasillando a los partidos a partir de un doble criterio: el eje cristiano/ secular y la ubicación del partido en el espectro izquierda-derecha. De ello se obtienen las siguientes categorías: derecha cristiana; centro derecha cristiana; izquierda cristiana; centro izquierda se-

la expansión de las asociaciones de trabajadores.

8 Mientras que la AD era un partido socialdemócrata, policlasista, populista, nacionalista, antioligárquico, antiimperialista y con una plataforma del modelo nacional popular, el COPEI «es la versión venezolana de los partidos socialcristianos europeos, inspirados en las ideas socialistas y la doctrina social de la Iglesia Católica». COPEI habría surgido con el objetivo de convertirse en una vía intermedia entre capitalismo y socialismo, siendo su principal ideólogo y fundador Rafael Caldera. Este partido registró una notable moderación desde posiciones iniciales más autoritarias (Di Tella, 1997; Méndez y Morales, 2001).

9 A estos partidos se agregan cerca de media docena de partidos de menor influencia en esa época. 
Andrés DockendorfF • El espejismo de la institución...

cular; izquierda secular y partidos personalistas ${ }^{10}$. Si se consideran solo a los partidos venezolanos que obtuvieron representación (al menos un escaño) y se extiende la clasificación del autor a las elecciones parlamentarias de 1998, se observa que más de 40 partidos obtuvieron representación parlamentaria en los 9 comicios para la Cámara Baja realizados en el período contemplado. Los partidos clasificados por Coppedge dan cobertura a todo el espectro ideológico en forma combinada con el criterio de religiosidad ${ }^{11}$. Dentro de los principales partidos, el COPEI es clasificado como "centro derecha cristiana"; la AD, la URD y La Causa Radical (LCR) corresponden a partidos de "centro izquierda secular»; y el PCV y el MAS son ubicados en la izquierda secular. Se aprecia un nutrido contingente de partidos «personalistas», que se articulaban en torno a la figura de un caudillo

10 Coppedge trabaja con todos los partidos que obtienen votos en las elecciones legislativas (diputados) entre 1958 y 1993 , aquí se seleccionaron solo aquellos partidos que obtuvieron escaños en la Cámara baja, añadiendo a su clasificación para el caso venezolano a los nuevos partidos que emergieron con representación parlamentaria en 1998.

11 Esta última no debe ser entendida como un clivaje al que se superpone el criterio ideológico. Más que constituir un clivaje u orientar programáticamente a los partidos, la posición de los partidos al el eje religiosidad da cuenta del origen, composición social y algunas orientaciones básicas. Destaca el COPEI, por su de calidad partido democratacristiano, pero aparte de este partido el criterio es menos relevante que el ideológico. regional, o eran impulsados por líderes de partidos tradicionales que crearon sus propias plataformas electorales.

La transformación del sistema partidista acontecida desde mediados de la década de 1990 se reflejó en la proliferación de plataformas electorales y partidos personalistas de cara a las elecciones presidenciales y parlamentarias de 1998. En total, 5 partidos personalistas, de acuerdo a las categorías elaboradas por Coppedge, obtuvieron representación en la Cámara Baja en esos comicios. Antes de la proliferación de estos nuevos partidos, el sistema partidista venezolano se caracterizó por dos cosas: su acentuado bipartidismo y el esquema de alternancia pendular entre los dos partidos principales, cuestiones que se revisan a continuación.

\section{Bipartidismo y alternancia «pendular»}

No existe una interpretación unívoca sobre la extensión y las características del bipartidismo en Venezuela. En su tesis doctoral, Abdón Vivas caracteriza la evolución del sistema de partidos en el marco más amplio de las continuidades y cambios del sistema político venezolano. Una primera etapa, entre 1958 y 1973, es definida como de "consolidación de la democracia», donde emerge y se consolida el bipartidismo (AD-COPEI). La segunda etapa es en propiedad la del «duopolio de partidos» (1973-1989), definida por el predominio absoluto de los dos grandes 
partidos, que desplazaron a las demás fuerzas del escenario político. En la tercera fase, de «equilibrio inestable» (1989-1998), se aprecia una progresiva erosión de la legitimidad del sistema partidista (Vivas, 2008: 105-110).

Según Alfredo Ramos, el bipartidismo es una característica de todo el período, donde una primera fase bipartidista (1958-1973) se sustentó en un alto nivel de centralización político-administrativa. En un segundo momento del bipartidismo, desde 1973, la partidocracia se extendió con mayor fuerza sobre el sistema político y la sociedad civil, de la mano con una creciente irrelevancia de la connotación programática de los partidos. La tercera y última fase comprende la desintegración del bipartidismo, dada la combinación del fraccionamiento partidario $\mathrm{y}$ un fuerte sentimiento anti-partidista con la regionalización y localización de la política (Ramos, 1999). Para otros estudiosos, no sería correcto hablar de un único sistema de partidos para el período estudiado, ya que entre 1958 y 1973 se desarrolló un sistema multipartidista limitado, seguido por un bipartidismo moderado (1973-1993) y finalmente el retorno a un sistema multipartidista limitado desde 1993 (Molina y Pérez, 1998b).

Lo concreto, a la luz de los datos electorales y la distribución de los escaños en el congreso, es que las únicas alternativas externas al bipartidismo, antes de 1993 vinieron desde la antigua izquierda guerrillera, agrupada en el Movimiento al Socialismo (MAS), que obtuvo votaciones en torno al 10\%, o bien de candidaturas independientes.

El bipartidismo se vio reflejado en el esquema de alternancia entre la AD y el COPEI. La rotación continua en el Ejecutivo de los dos partidos predominantes es considerada como una característica de largo plazo del sistema de partidos venezolano (Molina y Pérez, 1998b), a la que subyace una lógica explicativa asociada al desempeño gubernamental, la partidocracia y los constreñimientos institucionales.

\section{Cuadro $\mathrm{N}^{\mathrm{O}} \mathrm{I}$}

Alternancia en el Ejecutivo venezolano (I958-I998)

\begin{tabular}{|c|c|c|}
\hline Período & Partido & Presidente \\
\hline $1959-1963$ & AD & Rómulo Betancourt \\
\hline $1964-1968$ & AD & Raúl Leoni \\
\hline $1969-1973$ & COPEI & Rafael Caldera \\
\hline $1974-1978$ & AD & Carlos Andrés Pérez \\
\hline $1979-1983$ & COPEl & Luis Herrera Campins \\
\hline $1984-1988$ & AD & Jaime Lusinchi \\
\hline $1989-1993$ & AD & Carlos Andrés Pérez \\
\hline $1994-1998$ & COPEl & Rafael Caldera \\
\hline
\end{tabular}

Fuente: Consejo Nacional Electoral, División de Estadísticas. www.cne.ve. 
Andrés DockendorfF • El espejismo de la institución...

La alternancia se produce en la forma de un movimiento pendular entre la AD y el COPEI. Luego de un predominio de una década, la AD cedió el gobierno al COPEI, que obtuvo la presidencia liderado por su fundador Rafael Caldera. Este esquema de alternancia pendular se extendió al resto del período examinado, a excepción de la victoria del partido en el poder en 1988 (AD), de la mano del ex presidente Carlos Andrés Pérez. La insatisfacción con las políticas y el descontento con el desempeño de los gobiernos podrían explicar por qué los partidos que se encontraban en el gobierno no lograron retener la presidencia ${ }^{12}$. Esto puede desarrollarse conceptualmente a partir de lo que Torcal, Montero y Gunther (2007) definen como "antipartidismo reactivo» ${ }^{13}$. Para estos autores, el bajo rendimiento institucional y el descontento con los partidos lleva a los ciudadanos a adoptar una posición crítica que se nutre del fuerte desajuste entre las expectativas de las personas y la performance del gobierno y los partidos, lo que se ve acrecentado por la no resolución de problemáticas económicas y un empleo abusivo o arbitrario de los recursos públicos por parte de los líderes par-

12 Molina y Pérez (1998b) hablan de un «descontento endémico» con el rendimiento de los sucesivos gobiernos.

13 Los autores separan, teórica y empíricamente dos antipartidismos: uno cultural se despliega en el largo plazo sostenido por tradiciones históricas y una cultura política ad hoc, en ocasiones, en el marco de profundos procesos de socialización autoritaria de corte antipartidista. tidistas ${ }^{14}$. Los autores detectan que esa tipología de antipartidismo está asociada con una actitud más proclive a cambiar de gobierno. Si se extienden los hallazgos ${ }^{15}$ de Torcal y sus colegas al caso venezolano, la explicación propuesta adquiere sentido; la alternancia pendular fue el resultado de una insatisfacción constante con los gobiernos y sus políticas ${ }^{16}$.

La alternancia en el gobierno no era una situación traumática, ya que la $\mathrm{AD}$ y el COPEI tenían varios elementos en común. Ambos eran partidos multiclasistas con una base social diversificada

14 «En cierto sentido, es una consecuencia lógica de las promesas excesivas de los políticos, y de la utilización de un discurso político que eleva las expectativas de los ciudadanos hasta un punto que supera la mera posibilidad de cumplir todo lo prometido. Se trata también de una respuesta a fracasos reales de los partidos y de las elites. Muchos problemas sociales, económicos o políticos no se resuelven o no son afrontados satisfactoriamente. Con frecuencia, los líderes partidistas se comportan irresponsablemente, y muchos dirigentes utilizan de forma inadecuada su acceso a los recursos públicos, incurren en un comportamiento socialmente reprobable o realizan actividades calificadas de corrupción» (Torcal, Montero y Gunther, 2007: 248).

15 Realizados a partir de los datos de países del sur de Europa, y en este punto en particular, anclados en los datos de encuestas realizadas a los españoles.

16 «En la opinión pública predominaba el cuestionamiento a las instituciones, actores, valores y resultados de la democracia a la venezolana, con particular énfasis en la corrupción, la partidocracia y la impunidad» (Kornblith, 2003: 165). 
en torno a un liderazgo partidista central. Los dos contaron con un liderazgo profesional permanente, un alto nivel de nacionalización de la organización en los distintos niveles territoriales y una notable capacidad para incorporar a los grupos funcionales (por ejemplo, uniones laborales, estudiantes y asociaciones profesionales). Eran capaces de captar y movilizar importantes recursos financieros gracias a su control alternado del aparato gubernamental y la articulación de fuertes redes y vínculos con los sectores empresariales y el mundo financiero. Otro punto en común, es que los dos partidos desarrollaron capacidades técnicas para montar sofisticadas y costosas campañas electorales (Kornblith y Levine, 1993; Coppedge, 1993).

La mayor parte del período analizado muestra una alta concentración de la adhesión electoral de los venezolanos en torno a estos dos partidos. Los gráficos siguientes ilustran la evolución del predominio electoral de la AD y el COPEI en los comicios presidenciales (Gráfico $\mathrm{N}^{\circ}$ 1) y en las elecciones legislativas (Gráfico No 2).

\section{GrÁfico $\mathrm{N}^{\mathrm{O}} \mathrm{I}$}

EVOLUCIÓN DE LA VOTACIÓN PRESIDENCIAL AD-COPEI (I958-I998)

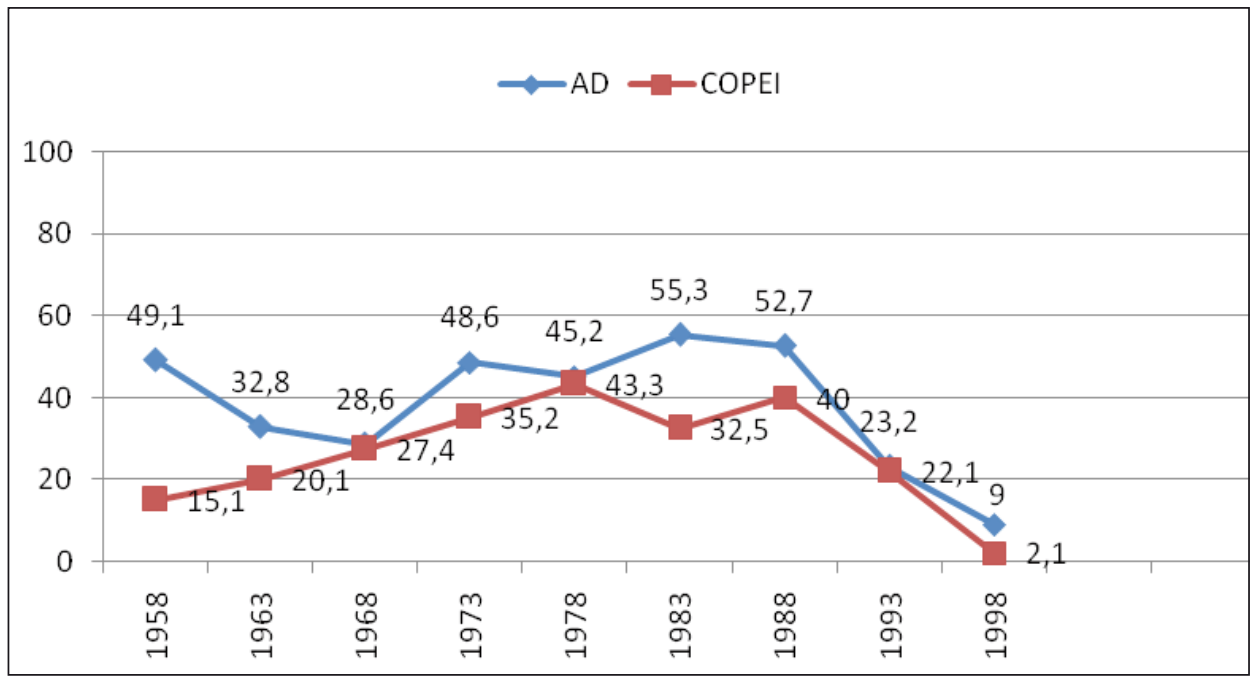

Fuente: Elaboración propia, con datos obtenidos del Consejo Nacional Electoral de Venezuela. www.cne.ve. 
ANDrÉs DockendorfF • El espejismo de la institución...

GRÁFICO N ${ }^{\circ}$

Presencia de la AD y el COPEI en la Cámara Baja (I958- i 998 )

(\% DE ESCAÑOS)

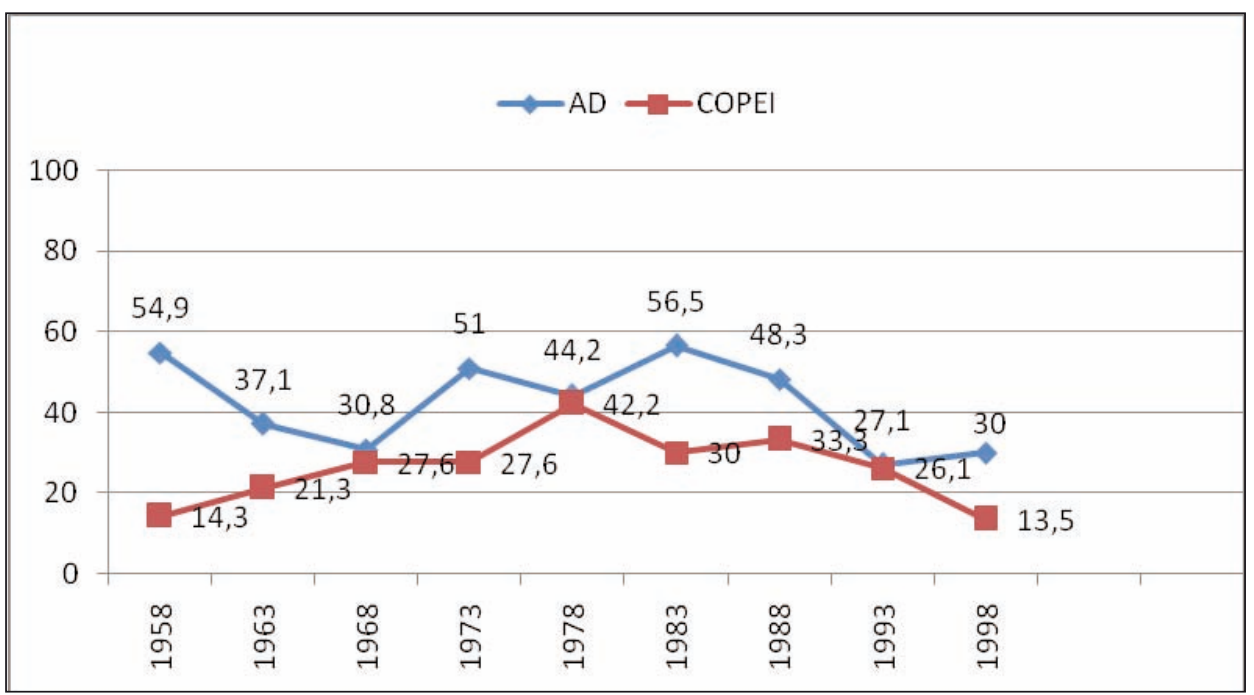

Fuente: Elaboración propia, con datos obtenidos del Consejo Nacional Electoral de Venezuela. www.cne.ve.

Hasta los comicios concurrentes de 1968 , la correlación de fuerzas electorales daba cuenta de un multipartidismo moderado, con dos partidos centrales, y uno de ellos predominante (AD). Esa situación se modificó en 1973. La concentración del voto presidencial fue particularmente fuerte entre 1973 y 1988. Ese predominio bipartidista se quebró en las elecciones de 1993, donde los «otros» partidos obtuvieron un $55 \%$ de la votación en la elección presidencial. En los comicios de 1993, la $\mathrm{AD}$ y el COPEI sumaron un $45 \%$ de los votos y en 1998 cayeron a un insignificante $11 \%$, muy lejos del $93 \%$ de la votación alcanzado en 1988 o del $87 \%$, en 1983. En cuanto al porcentaje de escaños obtenidos por los partidos en las elecciones para la Cámara Baja, la tendencia a la concentración bipartidista de los votos y escaños diputacionales fue igual de alta que en los comicios presidenciales, pero solo hasta 1993, cuando la AD y el COPEI vieron disminuida drásticamente su presencia en el congreso, $y$ «otros» partidos subieron desde un $18 \%$ de los escaños a casi el $47 \%$ de los curules. En 1998, la AD y el COPEI en conjunto obtuvieron un $43 \%$ de los escaños, muy por encima de la escuálida suma de su votación presidencial $(11.2 \%)$, reflejando la desestructuración del sistema partidista. Al respecto, la siguiente sección examina el proceso de institucionalización, des- 
composición y colapso del sistema de partidos venezolano.

\section{EL COLAPSO DE UN SISTEMA PARTIDISTA INSTITUCIONALIZADO}

Los estudios comparados sobre la institucionalización de los sistemas de partidos en América Latina en los años noventa daban cuenta de la notable estabilidad del sistema de partidos venezolano. En su conocido trabajo, Mainwaring y Scully (1995) concluían que el sistema partidista venezolano era uno de los más institucionalizados de la región ${ }^{17}$.

Los partidos venezolanos se caracterizaban por un alto nivel de disciplina y centralización, control absoluto del proceso de selección de candidatos, un rol protagónico en la competencia electoral, fuerte vinculación con los actores sociales y los grupos de interés y un notable arraigo de las lealtades electorales basadas en las etiquetas partidistas. En parte, esta optimista visión se entiende debido a que la mayor parte de los datos analizados para el caso venezolano contemplan el período 1973-1988 (algunos hasta 1993). Pese a las auspiciosas conclusiones, los autores advirtieron sobre el debilitamiento de los partidos en las elecciones de 1993. Estas introdujeron importantes cambios en la correlación de fuerzas partidistas, a lo que se agregaban la corrupción, los problemas económicos y las actitudes de los actores y parte de la población respecto de las intentonas golpistas de 1992.

La victoria de Rafael Caldera en 1993, apoyado por Convergencia y el MAS, rompió definitivamente con el bipartidismo mantenido desde 1958. Si bien la AD y el COPEI conservaron la mayoría en el congreso, con la elección de Caldera se legitimó la entrada definitiva de un nutrido contingente de nuevos partidos, la mayoría abiertamente críticos a los partidos tradicionales (Ramírez Roa, 2003).

La crisis del sistema partidista venezolano cubrió todos los criterios contemplados por Mainwaring y Scully: altos niveles de volatilidad electoral reemplazaron la estabilidad del período anterior; la legitimidad de los partidos se desplomó, siendo sustituidos por liderazgos regionales y outsiders; la capacidad organizativa de los antiguos y nuevos partidos se redujo significativamente, y las redes sociales de la antigua partidocracia también se debilitaron drásticamente (Molina, 2001). El cambio en la fisonomía del sistema de partidos se refleja parcialmente en la evolución de los escaños obtenidos por los distintos partidos entre 1958 y 1998. 17 Junto a los sistemas de Costa Rica, Uru-
guay y Chile. 
ANDrÉs DockendorfF • El espejismo de la institución...

TABLA $\mathrm{N}^{\mathrm{O}} 2$

Distribución de escaños en la CÁmara BAJa (I958-I998)*

\begin{tabular}{|c|c|c|c|c|c|c|c|c|c|}
\hline Partido & 1958 & 1963 & 1968 & 1973 & 1978 & 1983 & 1988 & 1993 & 1998 \\
\hline AD & 54.9 & 37.1 & 30.8 & 51.0 & 44.2 & 56.5 & 48.3 & 27.1 & 30.0 \\
\hline COPEI & 14.3 & 21.3 & 27.6 & 32.0 & 42.2 & 30.0 & 33.3 & 26.1 & 13.5 \\
\hline UDR & 25.6 & 16.3 & 7.9 & 2.5 & 1.5 & 1.5 & 1.0 & 0.5 & 0.5 \\
\hline PCV & 5.2 & & 2.3 & 1.0 & 0.5 & 1.5 & 0.5 & & 0.5 \\
\hline FDP & & 9.0 & 5.1 & & & & & & \\
\hline MEP & & & 11.7 & 4.0 & 2.0 & 1.5 & 1.0 & 0.5 & 0.5 \\
\hline MAS & & & & 4.5 & 5.5 & 5.0 & 9.0 & 11.8 & 8.2 \\
\hline LCR & & & & & & & 1.5 & 19.7 & 2.9 \\
\hline CONVER. & & & & & & & 12.8 & 1.9 \\
\hline MVR & & & & & & & & & 22.2 \\
\hline PRVZL & & & & & & & & & 3.4 \\
\hline PPT & & 16.4 & 14.6 & 5.0 & 5.6 & 4.0 & 5.4 & 1.5 & 7.2 \\
\hline OtrOS & & & & & & & & \\
\hline
\end{tabular}

Fuente: Elaborado con los datos entregados por el CNE: www.cne.ve."

Porcentaje de bancas obtenidas por los partidos en la Cámara de Diputados.

La AD y el COPEI vieron disminuida drásticamente su presencia en la Cámara Baja desde 1993, cediendo espacios a viejas fuerzas como el MAS y nuevas agrupaciones como La Causa R. "Convergencia», la facción que siguió a Rafael Caldera fuera del COPEI en 1993 obtuvo solamente un $12.8 \%$ de los escaños, a pesar de que su líder fue electo para la primera magistratura. Ello refleja los altos niveles de desestructuración y la erosión de las raíces sociales de los partidos. En 1998 surgieron nuevas fuerzas de izquierda que disputaron el voto obtenido por los partidos que crecieron o aparecieron intempestivamente en 1993, además de cercenar aún más la adhesión de los partidos tradicionales. La Causa $\mathrm{R}$ y Convergencia, de Caldera, vieron desplomarse su votación y su presencia en la Cámara Baja en 1998, produciéndose un trasvasije hacia MVR, PRYVZ, PPT y otras formaciones menores.

A partir de 1993 la inestabilidad se convirtió en un rasgo importante del sistema partidista. La literatura asume una estrecha relación teórica y empírica entre la estabilidad de los patrones de competencia interpartidista y el nivel de institucionalización del sistema de partidos. En general, se acepta que en los sistemas de partidos institucionalizados, los partidos relevantes suelen ser los mismos entre una elección y otra, obteniendo un porcentaje de votos y escaños relativamente estable. En cambio, en los sistemas débilmente institucionalizados, los partidos importantes suelen ir variando en el tiempo, irrumpiendo y desapareciendo constantemente de la arena política. La fuerza electoral y la 
representación parlamentaria de estos partidos fluctúa considerablemente entre una elección y otra (Jones, 2007:5).

En el caso venezolano, la evolución de la volatilidad electoral da cuenta de la acelerada transformación del sistema partidista. El índice de volatilidad electoral de Pedersen (1979) captura el cambio neto en votos o escaños de los partidos entre una elección y la siguiente, midiendo las ganancias o pérdidas de cada partido y dividiendo por 2 la agregación del cambio neto total. En el cuadro $\mathrm{N}^{\circ} 3$ se expone la volatilidad electoral (calculada sobre la variación en el porcentaje de escaños) entre 1963 y 1998 para la Cámara Baja.

\section{Cuadro $\mathrm{N}^{\circ} 3$}

Volatilidad Electoral en Venezuela: i963-I998

\begin{tabular}{|cc|}
\hline Años & Volatilidad \\
\hline 1963 & 32.4 \\
1968 & 26.5 \\
1973 & 27.8 \\
1978 & 14.3 \\
1983 & 15.2 \\
1988 & 13.2 \\
1993 & 34.2 \\
1998 & 44.6 \\
\hline Volatilidad media & 26.0 \\
\hline
\end{tabular}

Fuente: Calculado a partir de los datos entregados por el Consejo Nacional Electoral disponibles en www.cne.ve.

Entre 1978 y 1988 , período en el cual el sistema partidista estaba fuertemente concentrado en la AD y el COPEI, la volatilidad electoral promedio fue de 14.2. En 1993 la volatilidad electoral aumentó drásticamente, llegando a 34.2, mientras que en las elecciones de 1998 se registró el índice de volatilidad más alto en 40 años $(44.6 \%)$. La fuerte caída de los partidos que obtenían la mayor parte de la votación entre 1963 y 1988 , junto con la emergencia de nuevas fuerzas partidarias que desaparecían entre una elección y otra, explican el alto nivel de volatilidad electoral en 1993 y 1998.
De acuerdo con Mainwaring y Zoco (2007), la «fecha de nacimiento» de una democracia es un fuerte predictor de la volatilidad electoral. En las democracias «más viejas», las elites invierten en el desarrollo de partidos para competir en las elecciones. También se observan un mayor traspaso intergeneracional de la identificación partidaria y una mayor efectividad de los viejos partidos en reproducir lealtades, gracias a su capacidad de recompensar a sus seguidores. En cambio, en las democracias post 1978, argumentan los autores, los candidatos se apoyan cada vez menos 
ANDrés DockendorfF • El espejismo de la institución...

en los partidos, lo que produciría mayor inestabilidad electoral.

$¿$ Es aplicable al caso venezolano esta explicación? Al parecer no, ya que los partidos se estructuraron mucho antes de 1978 y recién entre 1978 y 1988 mostraron un índice de volatilidad media, decantando en una alta volatilidad en 1993 y 1998. A diferencia de lo que esperan Mainwaring y Zoco, en el caso venezolano se registró un retroceso de la estabilidad electoral y de la capacidad partidista para reproducir las adhesiones en el tiempo.

Los apoyos electorales se canalizaron a través de un reducido número de partidos durante gran parte del período analizado y la estabilidad del voto por los dos partidos principales fue mayor aún si se la contabiliza por separado. Más apropiadas para el caso venezolano parecen las conclusiones a que llegan Roberts y Wibbels (1999), quienes demuestran que la volatilidad electoral en América Latina es una función de corto plazo de los problemas económicos, las fragilidades institucionales de los regímenes democráticos y los sistemas de partido, así como también de la relativa fluidez de las estructuras de clivajes. En un trabajo reciente, Mainwaring, España y Gervasoni (2009) apoyan la primera explicación de Roberts y Wibbels para la volatillidad (como función de corto plazo de los problemas económicos).

Otro aspecto ligado a la estructuración del sistema partidista tiene que ver con la fragmentación. El Número Efectivo de Partidos (NEP), propuesto por Laakso y Taagepera (1979) da cuenta de los partidos significativos que conforman un sistema y se calcula sumando el peso relativo de cada partido y elevando al cuadrado la proporción de escaños. La sumatoria del peso porcentual de cada partido es dividida por 1. El número de partidos relevantes no es un tema secundario para el funcionamiento del sistema de partidos y el desarrollo del proceso político, ya que la existencia de tres o más partidos fuertes o significativos en el congreso dificulta la formación de gobiernos con mayorías parlamentarias estables o la generación de acuerdos en torno a las políticas (Payne et al., 2006: 81; Stein et al., 2006). En otras palabras, mayores grados de fragmentación complejizan la gobernabilidad.

La evolución del NEP en la Cámara Baja y el Senado muestra la mayor fragmentación del sistema de partidos venezolano desde 1993. En 1958 el NEP en la Cámara Baja era de 2.7, mientras que en 1998 fue de 6.2, dando cuenta de la desintegración del sistema partidista y del debilitamiento de la capacidad de convocatoria electoral de los partidos predominantes hasta fines de los años ochenta. El bipartidismo se reflejó en el NEP de la Cámara Baja y el Senado entre 1958 y 1988, incrementándose fuertemente en 1993 y 1998, lo que ilustra, junto a los demás indicadores, la transformación del sistema partidista que tuvo lugar entre 1958 y 1988.

Esta fragmentación también se aprecia en las escisiones operadas al interior de los principales partidos que 
Cuadro $\mathrm{N}^{\circ} 4$

Número Efectivo de Partidos (NEP): I958-1998

\begin{tabular}{|c|c|c|c|c|}
\hline & $\begin{array}{l}\mathrm{N}^{0} \text { de partidos } \\
\text { Cámara Baja }\end{array}$ & $\begin{array}{c}\text { NEP } \\
\text { Cámara Baja }\end{array}$ & $\begin{array}{l}\mathrm{N}^{0} \text { de partidos } \\
\text { en el Senado }\end{array}$ & $\begin{array}{c}\text { NEP } \\
\text { Senado }\end{array}$ \\
\hline 1958 & 4 & 2.7 & 4 & 2.3 \\
\hline 1963 & 8 & 5.0 & 6 & 4.0 \\
\hline 1968 & 11 & 5.8 & 9 & 4.5 \\
\hline 1973 & 10 & 2.7 & 6 & 2.4 \\
\hline 1978 & 11 & 2.7 & 3 & 2.2 \\
\hline 1983 & 11 & 2.5 & 3 & 2.0 \\
\hline 1988 & 11 & 2.9 & 4 & 2.5 \\
\hline 1993 & 10 & 5.5 & 5 & 4.5 \\
\hline 1998 & 20 & 6.2 & 11 & 5.2 \\
\hline
\end{tabular}

Fuente: Elaboración propia a partir de datos del Consejo Nacional Electoral disponibles en www.cne.ve.

conformaron el sistema partidista hasta 1993. El faccionalismo se intensificó entre 1993 y 1998, dando cuenta de los problemas que atravesaban los otrora monolíticos partidos venezolanos. De la $\mathrm{AD}$ se desprendieron dos sectores: APERTURA, compuesto por los seguidores del ex Presidente Carlos Andrés Pérez y RENOVACIÓN, liderado por Claudio Fermín, también ex AD. Del COPEI salió la facción Irene Sáez, que tras la pérdida de apoyo popular de la ex Miss Universo, respaldó a Proyecto Venezuela, de Henrique Salas Romer. La facción de Eduardo Fernández también se escinde de la AD. Del MAS salen facciones que apoyan al MVR de Chávez y que en 1999 forman la ID. La Causa R también muestra escisiones: La Causa $\mathrm{R}$, de Andrés Velásquez y el PPT, liderado por Pablo Medina (Lalander, 2000; Rivas Leone, 2002). El gobernador Henrique Salas Romer formó un nuevo partido regional, Proyecto Carabobo, transformándolo después en plataforma presidencial con el nombre de Proyecto Venezuela. La ex Miss Universo Irene Sáez también pavimentó su figura nacional desde una alcaldía y emergió como una figura política externa a la partidocracia venezolana. Mientras Salas impulsaba su propio partido (PRVZL), Sáez también presentó su partido IRENE, y recibió el apoyo de La Causa $\mathrm{R}$ (que finalmente optó por apoyar a Alfredo Ramos) y de Factor Democrático. Su opción comenzó a decaer cuando aceptó el apoyo del COPEI (Lalander, 2004: 54), lo que ilustra el descrédito por el que atravesaban los partidos tradicionales.

Para Steve Ellner, el faccionalismo y la fragmentación partidista se originaron en la combinación de la debacle económica y la crisis del sistema partidista, donde las políticas y soluciones ${ }^{18}$ en

18 Los alineamientos de las facciones y las principales disputas al interior de los principales partidos habrían sido impulsadas por las políticas neoliberales, de un 
Andrés DockendorfF • El espejismo de la institución...

torno a estas dos situaciones provocaron alineamientos al interior de los partidos, favoreciendo la faccionalización y las escisiones partidistas (Ellner, 1996).

Además, el faccionalismo se nutrió de diferentes cuestiones, entre ellas conflictos ideológicos, disputas personales y la competencia por los recursos organizacionales. En definitiva, ¿Qué explica la brutal transformación del sistema de partidos a comienzos de los años noventa? Más específicamente, ¿Cómo cambia de una elección a otra de forma tan drástica la fisonomía del sistema partidista? ¿Qué ponderación analítica debe otorgársele a las reformas electorales de fines de los años ochenta? A continuación se intenta dar respuesta a estas preguntas. Como se verá, se trata de un proceso de descomposición y desafección de largo plazo. En ese marco, las reformas políticas y electorales aceleraron el colapso del sistema, al eliminar las contenciones institucionales que favorecían la reproducción electoral de un sistema partidista cada vez menos representativo.

\section{El «bumerán» de las reformas electorales}

La literatura politológica tiende a prescribir efectos mecánicos del sistema electoral sobre el sistema de partidos. $¿$ Qué incidencia debe asignarse a los cambios en el diseño electoral sobre la brutal transformación del sistema de

lado, y las posiciones adoptadas ante las reformas políticas, de otro. partidos en Venezuela? ¿En qué medida los cambios en la institucionalidad electoral pueden haber contribuido al colapso del sistema de partidos? Entre 1958 y 1988, el sistema electoral para la Cámara Baja era de Representación Proporcional (RP) con listas cerradas y bloqueadas y fórmula D' Hondt para la conversión de votos en escaños de representantes. Las reformas de 1989 establecieron un sistema electoral mixto o de RP Personalizada, conservándose el esquema de lista cerrada y bloqueada para los escaños electos por RP y la fórmula D' Hondt. Hasta 1988, todos los escaños eran asignados a través de la RP, mientras que en 1993 solo el 45\% de los curules se completaron con este sistema. En 1998, el 50\% de los legisladores fue electo a través de RP y la otra mitad obtuvo su escaño en distritos uninominales (Willis y Pérez Liñan, 2005; Nohlen, 1995; Lucena, 2003).

¿Qué efectos sobre el sistema de partidos derivaron de las reformas?

En términos generales, la literatura concluye que tanto el sistema electoral binominal para el Senado como el sistema de RP plurinominal «imperfecto» vigente hasta 1989 para la elección de Diputados, contribuyeron a la concentración y al bipartidismo, al favorecer a los dos grandes partidos (Nohlen, 1995: 281, 282; Nohlen, 1992). No obstante, el Índice de Desproporcionalidad Electoral (IDE) entre 1978 y 1998 da cuenta de resultados relativamente proporcionales, en especial al compararlos con otros países de América Latina, tanto antes como después de la reforma electoral. 
CuAdro $\mathrm{N}^{\circ} 5$

Índice de Desproporcionalidad Electoral (CÁmara Baja)

\begin{tabular}{ll}
\hline Año & IDE \\
\hline 1978 & 4.22 \\
1983 & 4.97 \\
1988 & 4.02 \\
1993 & 3.85 \\
1998 & 5.42 \\
\hline
\end{tabular}

Fuente: Payne (et al., 2006).

La lista cerrada y bloqueada fue un elemento decisivo en la fuerte estructuración del sistema, ya que las dirigencias y cúpulas de los partidos vieron facilitada la acumulación de poder al interior de las organizaciones. Los miembros individuales de los partidos y los potenciales candidatos dependían completamente de las cúpulas partidarias, las que decidían quienes postulaban y confeccionaban las listas y el orden de los candidatos en ellas. La única posibilidad de ser electo era obteniendo el respaldo de la conducción del partido. Los votantes muchas veces no conocían a quienes postulaban al interior de una lista, lo que junto a la alta concentración del poder y el limitado acceso a este por parte de muchos parlamentarios individuales, limitó la articulación en el tiempo de los intereses de los votantes por parte de los representantes (Shugart, 1992; Lucena, 2003; Marenco, 2009). Ello generó excesivos niveles de disciplina y centralización, lo que se intentó modificar con las reformas electorales. En el fondo, gracias al diseño electoral, el sistema de partidos venezolano era artificialmente inmune al personalismo y a la fragmentación.

La reforma electoral modificó sustantivamente la institucionalidad electoral que proporcionaba esa inmunidad al sistema partidista y asignaba una desmesurada fuerza a las dirigencias partidistas, a pesar de que se mantuvo el sistema de lista cerrada y bloqueada en la mitad de escaños electos por la RP. La reforma al sistema electoral para la Cámara Baja introdujo mayores grados de personalización en la competencia electoral, restando poder a los partidos en el congreso. Erosionó la dependencia partidista de los congresistas y contribuyó a personalizar la representación (Paravisini, 1998) $)^{19}$, catalizando el colapso definitivo del sistema partidista.

Junto con la reforma electoral se introdujo la descentralización, estableciéndose elecciones directas para

19 Bajo el esquema anterior, los representantes tenían pocos incentivos para hacerse visibles ante los electores, ya que las cúpulas de los partidos tenían un peso incontrarrestable en los procesos de selección de candidatos, incluso en el caso de los candidatos del partido en el Gobierno. 
alcaldes y gobernadores. Esta reforma impulsó nuevos patrones de comportamiento entre los viejos actores, modificó la correlación de fuerzas en el ámbito político electoral ${ }^{20}$ y expandió el espacio competitivo, tanto al interior de los partidos como entre ellos (Kornblith, 2003: 165). Junto con la regla uninominal para las elecciones parlamentarias, la descentralización alteró significativamente las relaciones y procesos al interior de los partidos, lo que se aprecia en la formación de facciones antagónicas al interior de los conglomerados, varias de las cuales terminaron escindiéndose de los troncos partidarios tradicionales. La mayoría de los movimientos opositores en los años noventa (incluido el chavismo con MRB200 y luego MVR) surgieron gracias al proceso descentralizador ${ }^{21}$.

20 Ya con la primera elección directa de gobernadores se produjeron algunos cambios respecto del sistema de partidos previo: organizaciones políticas diferentes a la $\mathrm{AD}$ y el COPEI obtuvieron espacios de representación a nivel regional, generándose también el posicionamiento de liderazgos y personalidades a nivel regional, antes inexistentes, de la mano con una "ampliación» del espacio de representación partidista (Kornblith, 2003: 166). En la siguiente elección regional (1992) la AD disminuyó su presencia a nivel regional, creciendo el COPEI, y el MAS. El declive se evidenció fuertemente en 1995.

21 Desde el proceso de descentralización impulsado en la administración de Carlos Andrés Pérez en 1989, el MAS pasó a tener mayor presencia tanto en la elección de gobernadores y en la conformación de la coalición gubernamental en la presidencial de Caldera (Ramírez Roa, 2003: 139).
La descentralización se transformó en un bumerán para el nivel central, que impulsó su introducción con el propósito de desconcentrar el sistema político y revertir los crecientes niveles de crítica y desafección política de los venezolanos. Por el contrario, la reforma descentralizadora visibilizó y potenció la contradicción, con el choque entre las fuerzas centrales que la implementaron y los múltiples intereses y liderazgos regionales que emergieron explosivamente, acentuando la personalización del liderazgo político a escala nacional (Rivas Leone, 2006; Molina, 2009). Desde ese prisma, la descentralización sería una de las raíces de la fragmentación del sistema de partidos (Lalander, 2004).

Ahora bien, no es correcto desprender una mecánica de causa-efecto vinculada al cambio institucional, ya que la misma reforma electoral se inscribe en el marco de un proceso de cambio y crisis de la representación. Las reformas se introdujeron como respuesta a un diagnóstico crítico sobre la representación política, el rol de los partidos y la participación (Nohlen, 1992; Kornblith, 1997) ${ }^{22}$. Por ello, la secuencia lógica indica que más bien aceleraron el colapso del sistema de partidos. El sistema partidista anclaba parte de su

22 La ciencia política ha estudiado la relación entre el sistema electoral y la faccionalización del sistema partidista. En su estudio sobre las facciones en los partidos uruguayos, Morgenstern (2001) sostiene que las leyes electorales de Uruguay originan y sustentan la existencia de facciones que operan, jerarquizadas, al interior de partidos estructurados débilmente. 
fortaleza en las reglas electorales que fabricaban estabilidad electoral. El acelerado proceso de descomposición y colapso del sistema partidista que tuvo lugar en las elecciones de 1993 y 1998 se produjo ante la baja o nula capacidad adaptativa y la baja representatividad de un sistema de partidos despojado de un corsé institucional, el sistema electoral, que lo dotaba de una aparente estabilidad, bajo la cual se desarrollaba un galopante proceso de desafección política y electoral.

\section{Abstencionismo, desafección y legitimidad democrática}

La población en edad de votar (PEV) creció desde 3.370 .710 en 1958 a 13.577.150 cuarenta años después. La población inscrita se incrementó desde
2.913 .801 en 1958 a 11.013 .020 de venezolanos registrados en 1998. En 1958 un $86 \%$ de la PEV estaba inscrita en el registro electoral. En 1993, año de elecciones presidenciales y parlamentarias concurrentes, un $80 \%$ de la PEV estaba inscrita para votar, cifra que se mantiene en 1998 (81\%). En 1958, la votación válida representó un $77 \%$ de la PEV, y el promedio entre 1958 y 1988 fue de $73 \%$. En 1993 la votación válida respecto a la PEV bajó drásticamente a un $46 \%$, y en 1998 subió levemente a $51 \%$. Aparentemente, el problema no era la inscripción de los ciudadanos. En cuanto a la votación nula, también aumentó en 1998. Entre 1973 y 1993 el porcentaje de votos nulos sobre la votación emitida fue de 3\%, llegando a $6.5 \%$ en 1998 .

Cuadro $\mathrm{N}^{\circ} 6$

Participación electoral y AbStencionismo (i958-i998)

\begin{tabular}{cccccc}
\hline Año & $\begin{array}{c}\text { Abstencionismo } \\
\text { (absoluto) }\end{array}$ & $\%$ & $\begin{array}{c}\text { Abstencionismo } \\
\text { PEV }\end{array}$ & $\%$ & $\begin{array}{c}\text { Abstención Total y } \\
\text { Votación Nula }\end{array}$ \\
\hline 1958 & 191.748 & $6,6 \%$ & 648.657 & $19.3 \%$ & $22.5 \%$ \\
1963 & 262.441 & $7,8 \%$ & 801.593 & $20.5 \%$ & $25.3 \%$ \\
1968 & 135.311 & $3,3 \%$ & 617.983 & $13.3 \%$ & $19.5 \%$ \\
1973 & 164.935 & $3,5 \%$ & 1.067 .813 & $18.9 \%$ & $22.5 \%$ \\
1978 & 775.103 & $12,5 \%$ & 1.868 .120 & $25.5 \%$ & $27.1 \%$ \\
1983 & 952.712 & $12,2 \%$ & 2.027 .580 & $22.9 \%$ & $24.9 \%$ \\
1988 & 1.660 .887 & $18,1 \%$ & 2.791 .560 & $27.0 \%$ & $29.1 \%$ \\
1993 & 3.859 .579 & $39,8 \%$ & 6.183 .744 & $51.4 \%$ & $53.3 \%$ \\
1998 & 4.013 .622 & $36,5 \%$ & 6.577 .752 & $48.4 \%$ & $51.7 \%$ \\
\hline
\end{tabular}

Fuente: Elaborado a partir de los datos proporcionados por el Consejo Nacional Electoral: www.cne.ve. Los datos corresponden a los comicios presidenciales. El voto y la inscripción eran obligatorios desde 1958 y el incumplimiento aparejaba una multa de 10 a 25 días de salario o arresto proporcional. 
ANDrés DockendorfF • El espejismo de la institución...

El cuadro $\mathrm{N}^{\circ} 6$ muestra el incremento de la abstención total de la votación nula $^{23}$ entre 1958 y 1998 . En cuanto al abstencionismo, las elecciones de 1993 representaron un punto de inflexión respecto de más de tres décadas de competencia electoral. Por regla general, los estudiosos que han tratado la abstención en Venezuela emplean la relación entre la votación total emitida o la votación válida respecto de la población inscrita para votar. Esta medida no refleja la brutal transformación en los patrones de asistencia electoral desde los comicios de 1993. Aun así, la abstención sobre la población registrada se duplicó en las elecciones de $1978(12.5 \%)$ respecto de los 20 años anteriores. En las elecciones de 1988 un $18 \%$ de los inscritos no asistió a votar.

En 1993 casi un 40\% de las personas registradas para votar no asistió a las urnas, porcentaje que disminuyó levemente en 1998. Al observar la abstención respecto de la PEV, se aprecia que alrededor de un $20 \%$ de los venezolanos habilitados para inscribirse y votar no lo hizo entre 1958 y 1983 . En 1993, más de la mitad de los venezolanos en edad de votar no acudió a las urnas en las elecciones presidenciales en las que resultó electo por segunda vez Rafael Caldera, tendencia que se mantuvo en 1998. La evolución del porcentaje de no inscritos y de inscritos

23 La abstención total y la votación nula corresponden a la suma de la abstención formal (inscritos que no acuden a votar), la votación nula y la PEV que no se registra y no vota. que se abstienen de votar da cuenta del agudo desfase entre la ciudadanía y el sistema de partidos. En 1993 la desafección electoral alcanzó a un $53 \%$ y en las elecciones presidenciales de 1998 fue de un $51.7 \%$, duplicando el promedio de los treinta años anteriores.

Las explicaciones en torno a la abstención suelen centrarse en el desgaste del sistema de partidos y en un creciente y extendido malestar con la política, el liderazgo político y los partidos. Otra explicación, que gira en torno a la variable institucional, ha hecho hincapié en la reforma que eliminó la obligatoriedad del voto, haciendo de este un ejercicio voluntario. No obstante, en las elecciones de 1993, donde se dispara la abstención, el voto todavía era obligatorio, por lo que resulta incorrecto afirmar que la reforma que instauró la voluntariedad del sufragio incidió directamente en el incremento del abstencionismo. Las causas habría que buscarlas en el bajo interés que despertaban las elecciones (Fernández, 1998) y en el creciente rechazo hacia las formas tradicionales de hacer política (Keoneke, 2000; Montillo, 2001). Esto coincide con los hallazgos de otros trabajos que han explorado las razones de la abstención en Venezuela en elecciones más recientes y que concluyen que esta puede entenderse como una forma de protesta política (Brandler, 2006) ${ }^{24}$. ¿Tuvieron un correlato en el apoyo a la democracia los crecientes niveles

24 En su investigación Brandler se soporta en información cualitativa. 
de abstencionismo? Antes de ello, ¿es correcto tratar la problemática del sistema de partidos en el marco de una crisis general de la democracia? Montero, Gunther y Torcal (1998) y Torcal (2003) diseccionan teórica y empíricamente los conceptos de legitimidad democrática, desafección política e insatisfacción democrática. El primero se mantiene aislado respecto a los dos últimos. La legitimidad democrática puede mantenerse alta en el tiempo a pesar de que existan altos niveles de desafección política y insatisfacción democrática. Es decir, se trata de dimensiones actitudinales independientes. Estas prescripciones parecen verse corroboradas a nivel demoscópico por los datos de opinión pública disponibles para Venezuela en los años noventa (ver Cuadro $N^{\circ} 7$ y Gráficos 3 y 4).

\section{CuAdro $\mathrm{N}^{\circ} 7$ \\ Preferencia democrática en Venezuela}

\begin{tabular}{ccccc}
\hline $\begin{array}{c}\text { Preferencia } \\
\text { democrática }\end{array}$ & $\begin{array}{c}1983 \\
\text { (BATOBA) }\end{array}$ & $\begin{array}{c}1993 \\
\text { (IEDPDP) }\end{array}$ & $\begin{array}{c}1995 \\
\text { (Valores) }\end{array}$ & $\begin{array}{c}1998 \\
\text { (REDPOL) }\end{array}$ \\
\hline Demócrata & $87 \%$ & $87 \%$ & $86 \%$ & $79 \%$ \\
No Demócrata & $13 \%$ & $13 \%$ & $14 \%$ & $21 \%$ \\
\hline
\end{tabular}

Fuente: Pereira (2002).

\section{GRÁfico $\mathrm{N}^{\circ} 3$}

PREFERENCIA POR EL SISTEMA DEMOCRÁTICO

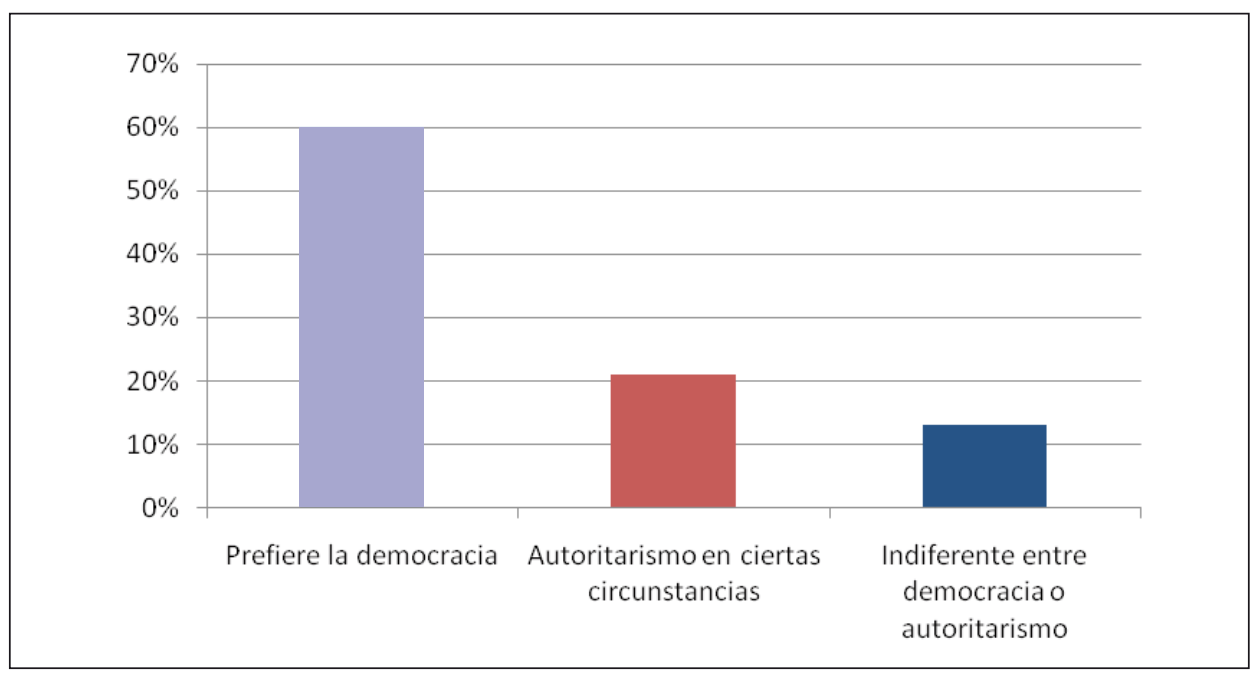

Fuente: Latinobarómetro 1995. 
De acuerdo a los datos recogidos por Latinobarómetro, entre 1996 y 2000 un $61 \%$ de los venezolanos prefería la democracia. Como se aprecia en el Gráfico $\mathrm{N}^{\circ}$ 3, en 1996 y 1997 un $63 \%$ de los venezolanos prefería la democracia a un gobierno autoritario (18\%), en tanto que un $14 \%$ de los encuestados se manifestaba indiferente entre un gobierno democrático y uno autoritario.
La preferencia democrática también era consistentemente fuerte desde 1983, como lo evidencian distintos estudios de opinión en los que se preguntó al respecto, donde una mayoría se declaraba como demócrata (Cuadro $\mathrm{N}^{\circ} 7$ ). Otra cosa ocurre si el foco se desplaza a los datos de opinión pública sobre la satisfacción de los venezolanos con la democracia (Gráfico No ${ }^{\circ}$ ).

\section{GRÁFICO N ${ }^{\circ} 4$}

Satisfacción Con la democracia (Muy/ Considerablemente satisfecho)

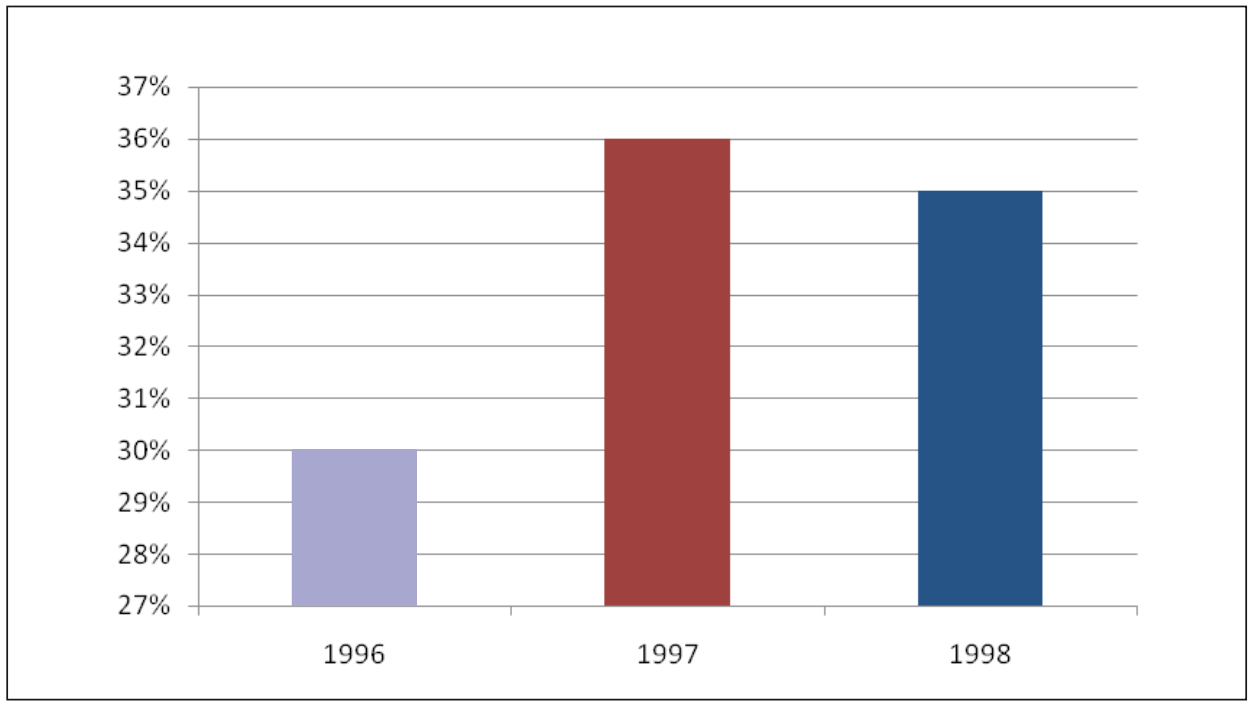

Fuente: Latinobarómetro 1996, 1997 y 1998.

La satisfacción con la democracia era baja en la década de 1990. En 1996, solo un $30 \%$ de los encuestados por Latinobarómetro señalaba estar «muy satisfecho/ considerablemente satisfecho» con la democracia. En 1997, 36\% estaba satisfecho con la democracia, y un $35 \%$ en 1998. Mientras tanto, un porcentaje marginal de los venezolanos entrevistados en 1995 y 1996 mostraba confianza en los partidos (Ver Gráfico $\mathrm{N}^{\circ} 5$ ), lo que fue configurando un conjunto de actitudes y percepciones que conformaron un síndrome de desafección política en Venezuela. 
GRÁFICO ${ }^{\circ} 5$

Confianza en los PaRtidos (Mucha/ Algo de Confianza)

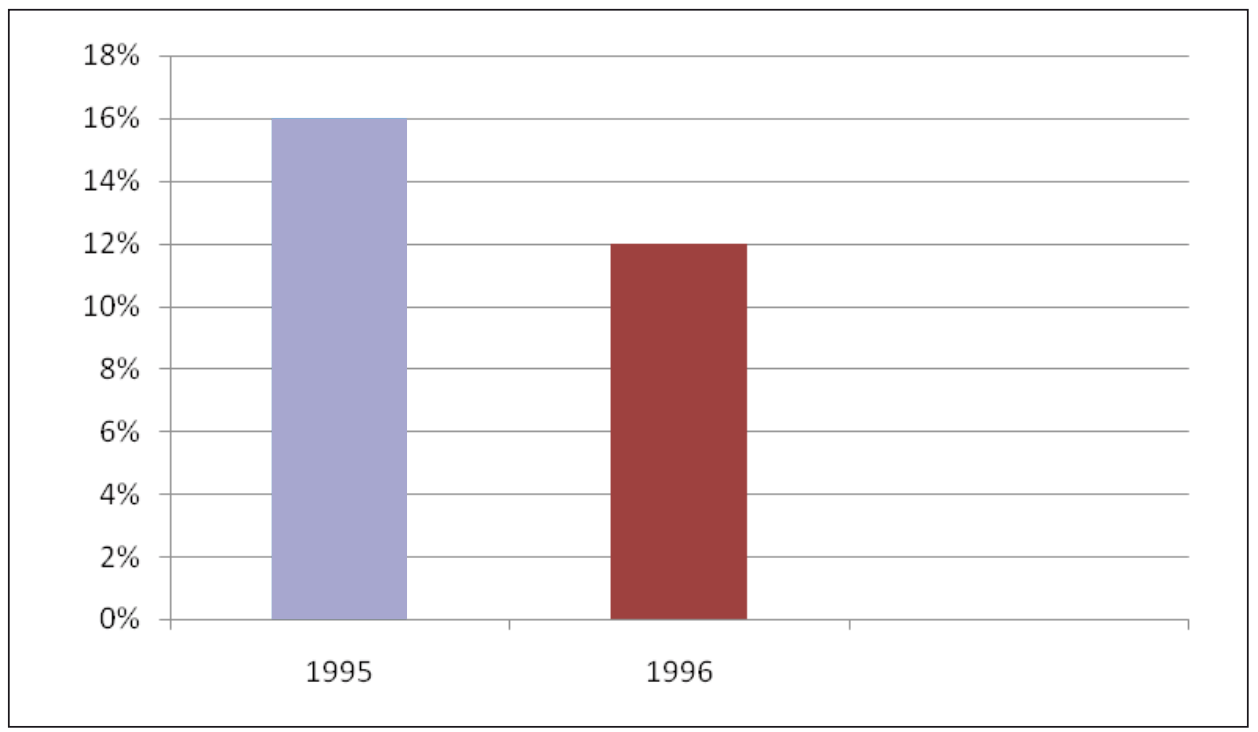

Fuente: Latinobarómetro 1995, 1996.

El apoyo de los venezolanos a la democracia fue alto entre 1983 y 1998 y se mantuvo aislado, tal como lo señalan Montero, Gunther y Torcal (1998) y Torcal (2003), respecto de la eficacia o rendimiento de la democracia y la desafección política. Mientras, la baja confianza en los partidos políticos tampoco parece haber afectado directamente la legitimidad de la democracia. Los venezolanos seguían apoyando la democracia sobre una alternativa autoritaria. Lo anterior, a pesar de la precaria confianza en los partidos, la baja satisfacción con el funcionamiento de la misma democracia y el hecho de que una mayoría de los venezolanos no se interesaba en la política en los momentos en que el sistema de partidos estaba próximo al colapso. Una vez descartada la presencia de actitudes anti-democráticas, es factible concluir que la crisis nunca fue al nivel del régimen democrático.

\section{III.¿POR QUÉ COLAPSÓ EL SISTEMA} DE PARTIDOS VENEZOLANO?

\section{EXPLICACIONES ALTERNATIVAS}

Una primera explicación para el colapso del sistema de partidos está centrada en las actitudes y posiciones adoptadas por los partidos y el liderazgo político respecto de los intereses organizados, la sociedad, la competencia electoral y el rendimiento de los partidos en el gobierno. Si bien los 
notables resultados electorales de la $\mathrm{AD}$ y el COPEI en el apogeo del bipartidismo conllevaron un alto nivel de estabilidad y gobernabilidad, esta hegemonía también fue incubando una insatisfacción que finalmente produjo inestabilidad. La excesiva centralización de los procesos de selección de candidaturas y confección de las listas amplificaron el poder de los dirigentes y las cúpulas de los principales partidos. Los representantes dependían completamente de la voluntad del partido, lo que derivó en una férrea disciplina partidista, pero a la vez fue alejando a los parlamentarios de sus electores, debilitando con ello el vínculo representativo. Los representantes no tenían incentivos para hacerse visibles ante las bases o promover políticas más próximas a los intereses de sus electorados ${ }^{25}$.

A estos partidos que controlaban gran parte del aparato público y las organizaciones civiles se añadieron representantes «poco receptivos», lo que resultó intolerable para la población (Levine y Crisp, 1999). En forma opuesta a lo que acontece en muchos países de América Latina, donde la indisciplina de los legisladores obstaculiza la fluidez del proceso de formulación de políticas y la ejecución de los programas de los gobiernos, operando como restricción para la gobernabilidad, en Venezuela los altos niveles de disciplina parlamentaria derivados del

25 Sus posibilidades de reelección tenían que ver más con las decisiones tomadas por las directivas del partido. férreo control del proceso de selección y nominación de candidatos fueron incubando un creciente malestar hacia los partidos y los representantes.

La omnipresencia de los partidos en las agrupaciones y organizaciones de la sociedad civil reforzó la percepción de que estos partidos controlaban todos los espacios de representación. Lo paradojal es que esta percepción adquirió mayor resonancia pública precisamente cuando los partidos empezaron a ver deteriorada su presencia y control en las organizaciones de la sociedad civil. Por ello, el sistema partidista llegó a la década de 1980 deteriorado por dos flancos: en su representatividad y en la imagen proyectada a la ciudadanía, por un lado, y por otro, en sus poderes partidarios (Coppedge, 2001).

Las viejas organizaciones del bipartidismo fueron perdiendo progresivamente su arraigo popular, aumentó su indefinición ideológica y se debilitó considerablemente la percepción sobre su capacidad para manejar y dirigir los asuntos públicos. En suma, un conjunto de factores incidió en la descomposición del sistema de partidos y la entrada al juego de nuevos actores. Entre ellos se cuentan la visión negativa sobre los partidos, la mala evaluación de los que ocupaban el poder y las expectativas de un mejor desempeño cifradas en los nuevos partidos (Morgan, 2007: 94).

No obstante, los nuevos partidos tampoco consiguieron una adhesión estable de un electorado crecientemente desafecto de las fuerzas tradicionales (Kornblith, 1994). La extraordinaria 
capacidad del sistema de partidos, desde 1958, para movilizar a sus miembros y apoyos en pos de la estabilidad del sistema político fue vital en la reproducción de la gobernabilidad y la legitimidad pero, implicó confinar la participación a los actores claves del 58. Los altos niveles de institucionalización del sistema partidista ${ }^{26}$ no dieron cuenta de las consecuencias del extremo opuesto a la sub-institucionalización. La literatura también reconoce que los sistemas de partidos excesivamente institucionalizados, que giran en torno a uno o dos partidos, pueden llegar a ver disminuida la eficiencia y efectividad de la representación política (Prud' Homme, 2001).

En relación con lo anterior, Andreas Schedler (1995) sostiene que si bien las instituciones pueden caracterizarse por ser débiles, también pueden ser excesivamente fuertes. En el segundo caso se inscriben los sistemas de partidos hiperinstitucionalizados, que se caracterizan por bajos niveles de incertidumbre, ciudadanos indiferentes, un mercado político cerrado en que predomina la colusión de los partidos existentes, niveles precarios de accountability (vertical y horizontal), baja credibilidad de los liderazgos partidistas y un antipartidismo latente. Estos sistemas de partidos pueden mostrar bajos niveles de

26 Medido en la estabilidad de las adhesiones electorales, la alta penetración partidista de la sociedad civil, el reconocimiento y aceptación de las reglas para competir y acceder a los cargos públicos y al gobierno, y la fortaleza organizativa de los partidos. volatilidad, en forma conjunta con un deterioro de los vínculos entre partidos y votantes (Schedler, 1995: 24). En el caso venezolano, el dominio excesivo de los partidos, su extremo pragmatismo, la corrupción y la ausencia de control, contribuyeron a rezagar al liderazgo político respecto de las transformaciones sociales (Kornblith, 1997).

En este punto adquiere importancia una advertencia realizada por Mainwaring y Scully, quienes señalaron que la estabilidad de las reglas y los patrones de competencia, en tanto requisito para la institucionalización, no validaba la imagen de congelamiento del sistema. Por el contrario, si bien la estabilidad es una característica distintiva de los sistemas de partidos institucionalizados, la proyección de los partidos en el tiempo tiene que ver con su capacidad adaptativa respecto de los cambios en el entorno. Los partidos venezolanos mostraron una limitada capacidad adaptativa, sosteniéndose únicamente en la alimentación de los vínculos clientelistas. Desde una panorámica comparada, que también incluye el caso venezolano, Coppedge (2000) habla de "darwinismo político", aludiendo a la supervivencia de los partidos que fueron capaces de adaptarse al ambiente político de la «década perdida»-de estancamiento económico y austeridad- que va desde los año ochenta a mediados de la década de 1990. Los partidos que no se adaptaron a este proceso de selección natural fueron reemplazados por nuevos partidos con características organizativas 
Andrés DockendorfF • El espejismo de la institución...

diferentes. Para la consolidación de sistemas de partidos «verdaderamente democráticos» resulta fundamental la capacidad y flexibilidad del sistema para cambiar y adaptarse a las transformaciones y nuevas demandas de la sociedad (Cavarozzi y Casullo, 2004). Los partidos venezolanos carecieron de capacidad adaptativa. Por el contrario, se petrificaron, contribuyendo decisivamente al colapso del sistema.

Una segunda línea analítica pone el acento en el cambio de las condiciones económicas, que impidieron la proyección del modelo rentista y por ende, de un sistema partidista crecientemente sostenido en el clientelismo redistributivo. Desde la década de 1980, la crítica del sistema político por su incapacidad de mejorar las condiciones de vida de buena parte de la población, además de la corrupción existente, erosionaron la legitimidad de los partidos y gatillaron un descontento cuyo foco principal fueron, precisamente, las organizaciones partidistas (Kornblith y Levine, 1993, Pérez, 2003). La insatisfacción con las políticas y los gobiernos se traducía en un voto por la oposición, lo que denominamos alternancia pendular. No obstante, la profundización de la insatisfacción y el descontento implicó que el malestar se dirigiera hacia ambos partidos (Pérez, 2003).

La disminución de los precios del petróleo en 1982 y la dificultad para conseguir créditos derivó en la crisis de la deuda externa, que provocó cambios en la política económica rentista, dislocando severamente el eje en el cual se sostenía el sistema de partidos. ${ }^{27}$ Este último se anclaba en vínculos corporativos establecidos con sectores patronales y organizaciones de trabajadores, por un lado, y lazos basados en intercambios clientelares con parte de la población, por el otro. Con el transcurso del tiempo estos vínculos pasaron a depender cada vez más de la redistribución y de las variadas intervenciones estatales destinadas a subsidiar el consumo y proteger la producción. La caída de la renta petrolera y la crisis de la deuda erosionaron esta «forma de representación política» y pusieron a los partidos en el centro de la crítica (Roberts, 2003; Roberts, 2001).

La crisis se amplificó rápidamente debido a que se había instalado una «mentalidad rentista», de acuerdo con la cual las diversas demandas materiales pasaron a formularse en exigencias a las cuales el Estado debía dar respuesta inmediata (Lander y Fierro, 1996). Se generó un dramático desajuste entre las expectativas de la población y el rendimiento gubernamental, mermado por el deterioro de la capacidad rentista. La gobernabilidad entró en crisis y el sistema de partidos se mostró incapaz de operar efectivamente en un escenario de mayor complejidad, en el cual los partidos ya no contaban con los recursos necesarios para obtener y reproducir los apoyos. Buena parte del análisis anterior parte del supuesto de

27 Sobre las características de la crisis del sistema rentista y sus efectos políticos y sobre el sistema de partidos, véase, Lander y Fierro (1996) y Salamanca (1994). 
que la institucionalización del sistema de partidos se nutre exclusivamente de la existencia de vinculaciones programáticas entre partidos y votantes. Al respecto, Herbert Kitschelt advierte que la institucionalización de la competencia partidista puede conseguirse a través de vínculos (linkages) no programáticos (Kitschelt, 2000: 853). Aceptando lo anterior, resulta plausible sostener que el sistema de partidos obtuvo parte de su institucionalización sobre la base del predominio de vínculos clientelistas.

Las dos explicaciones expuestas permiten concluir, tentativamente, que se trató de un proceso en que, por un lado, las estrategias, posiciones y actitudes de partidos con una baja capacidad adaptativa fueron erosionando su legitimidad y la representatividad de un sistema partidista hiperinstitucionalizado $y$, por el otro, el bajo rendimiento gubernamental aceleró el descrédito de los mismos partidos que controlaron el aparato estatal durante más de tres décadas y que a medida que perdían su habilidad para representar a los ciudadanos en función de lineamientos ideológicos y programáticos, sustentaron sus plataformas electorales únicamente en los vínculos basados en intercambios clientelares, esquema que se hizo inviable una vez agotado el modelo rentista.
Las limitaciones de la

institucionalización del sistema

partidista como perspectiva analítica

¿Por qué los estudios sobre la institucionalización del sistema de partidos en los años ochenta y noventa no previeron el proceso de descomposición y colapso del sistema de partidos venezolano? Una primera respuesta, enfocada en la metodología y los supuestos teóricos en que descansa el estudio de la institucionalización cuestiona la «lógica aditiva y unidimensional» del enfoque de Mainwaring y Scully, lo que limitaría su alcance, y explica por qué: «(...) sistemas descritos como institucionalizados a mediados de los 90' hayan atravesado por profundas crisis, llegando en algunos casos al colapso en los años subsiguientes» (Luna, 2007: 398). Por otro lado, los criterios empleados por Mainwaring y Scully, replicados por la investigación convencional, no corresponden completamente al nivel sistémico, es decir, a los patrones de interacción competitivos entre los partidos. A excepción del criterio que mide la estabilidad de la competencia interpartidaria (volatilidad), el enfoque analiza a los partidos individualmente, por lo que más bien capta la institucionalización partidista (Randall y Svassand, 1999; Markowski, 2000; Rodríguez, 2007).

Emplear indicadores de institucionalización partidista para el análisis a nivel sistémico presume una relación fuerte entre la institucionalización 
Andrés DockendorfF • El espejismo de la institución...

partidista y la institucionalización del sistema. ¿Están efectivamente relacionados ambos niveles? Es decir, ¿existe una asociación empírica no contingente entre la institucionalización de los subsistemas y el sistema en su conjunto? Las respuestas a estas preguntas están lejos de confirmar meras tautologías. En su estudio comparado del caso polaco, Radoslaw Markowski encuentra poco convincente el vínculo directo entre la institucionalización de los partidos y la estabilización del sistema. La relación entre estas dimensiones -individual y sistémica- dista de ser simple y determinística. En algunos casos, la institucionalización de los partidos, su estabilidad organizacional y su continuidad pueden conducir a la institucionalización del sistema, pero es altamente probable que no sea así en otras circunstancias, particularmente en el caso de democracias jóvenes. Más que estructuras organizacionales estables (a nivel individual), la institucionalización de los sistemas partidistas requiere flexibilidad y adaptabilidad frente a contextos de veloz cambio social (Markowski, 2000).

De esa forma, el análisis de la institucionalización que se centra en la dimensión individual termina contemplando la estabilidad de los subsistemas y no del sistema como un todo. Se trata de dos fenómenos analíticos diferentes: la institucionalización estática y la «institucionalización dinámica» del sistema de partidos, lo que requiere indagar sobre la «calidad de la estabilidad» (Markowski, 2000).
Randall y Svassand (1999) coinciden con lo anterior y plantean la inconveniencia de asumir que la institucionalización individual de los partidos está asociada con la institucionalización a nivel sistémico. No necesariamente, y no siempre ambas dimensiones son compatibles. La confusión conceptual existente omitiría una tensión potencial entre la institucionalización individual de los partidos y el nivel sistémico. ¿Cómo captar el proceso de descomposición de la hiperinstitucionalización y los síntomas del colapso a nivel sistémico si lo que se analiza preferentemente son los partidos (subsistemas) y no las continuidades y discontinuidades en los patrones de interacción que delimitan los contornos y las características de un sistema partidista? Difícilmente van a ser identificadas las propiedades y regularidades que dan forma a la competencia entre los partidos, si el enfoque y los criterios que se emplean segmentan el análisis en las unidades, y no en las coordenadas competitivas sobre las cuales se despliegan los patrones de interacción ya descritos.

Por otro lado, y a pesar de que Mainwaring y Scully (1995: 18) señalan que su argumento no implica un «prejuicio teleológico hacia la hiperinstitucionalización», su enfoque y los criterios de análisis y medición que desarrollan no ponderan adecuadamente las dinámicas y las consecuencias sistémicas asociadas a un sistema hiperinstitucionalizado, identificadas por Schedler.

En Venezuela, la excesiva fortaleza de los partidos condujo a lo que deno- 
minamos espejismo de la institucionalización. La fuerza individual de la $\mathrm{AD}$ y el COPEI proyectó la imagen de un sistema partidista estable e institucionalizado, por un lado, y por otro, reforzó la idea de que una vez conseguida la institucionalización, esta es irreversible. En el fondo, se trata de una perspectiva analítica unidireccional, incapaz de recoger los cambios regresivos producidos una vez que el sistema se institucionalizó y eventualmente, los efectos de la hiperinstitucionalización.

De todas formas, si se reconstruye el análisis de la evolución del sistema de partidos entre 1958 y 1998 a partir del enfoque y los criterios propuestos por Mainwaring y Scully, con las ventajas obvias de hacer ese ejercicio ex post, y a riesgo de caer en cierto determinismo retrospectivo, se reconocen parcialmente los síntomas de descomposición y colapso que derribaron el sistema partidista a fines de los años noventa.

En primer lugar, la alta volatilidad electoral en 1993 y 1998 daba cuenta de las dificultades de los partidos por mantener su adhesión electoral y proyectarse en el tiempo, volviendo irregular la competencia entre los partidos, en el contexto de un decrecimiento electoral de los partidos tradicionales y de la irrupción de nuevos partidos, algunos de los cuales desaparecían en la elección siguiente.

Respecto de las raíces sociales de los partidos (segundo criterio), Mainwaring y Scully postulaban que la diferencia entre las votaciones presidencial y legislativa, por un lado, y la sobrevivencia electoral de los partidos, por el otro, permiten evaluar el grado de arraigo social de los partidos. Entre 1958 y 1993, la diferencia entre la adhesión electoral obtenida en las elecciones presidenciales y parlamentarias en Venezuela fue marginal. En 1998, esta diferencia se amplió espectacularmente en comparación con el período anterior. En cuanto a la supervivencia electoral de los partidos venezolanos, en 1998 los partidos existentes en 1993 obtuvieron un $44 \%$ de los escaños.

¿Qué refleja lo anteriormente expuesto en relación con el arraigo social de los partidos y la fortaleza de los vínculos entre estos y los electores? $¿$ Constituyen la diferencia entre la votación presidencial y legislativa o la supervivencia de los partidos indicadores poderosos sobre la fortaleza de las raíces sociales de los partidos? No necesariamente, ya que una alta congruencia en el volumen de ambos votos puede deberse también a otros factores, como el mayor o menor control del proceso electoral, la modalidad de conformación de las listas parlamentarias o a la capacidad de arrastre de los liderazgos presidenciales, entre otros. Por otro lado, estos indicadores no recogen situaciones de descomposición o deterioro de los vínculos entre votantes y partidos, particularmente imperceptibles para la calculadora.

$\mathrm{Al}$ indagar en los vínculos entre ciudadanos y partidos, lo obvio parece ser recurrir a datos de opinión pública, donde se obtienen conjuntos de percepciones relativas a los partidos políticos. 
ANDrés DockendorfF • El espejismo de la institución...

Mainwaring y Scully no contaban con estudios regionales comparables como los realizados por Latinobarómetro ${ }^{28}$. Los datos perceptivos sobre identificación partidaria, preferencias electorales y confianza en los partidos, captan una parte fundamental de los vínculos entre ciudadanos y partidos, y de paso, la fortaleza de las raíces sociales de los partidos. Esto se recoge en el trabajo de Payne y otros (2006), donde a pesar de que se sigue la arquitectura teórica propuesta por Mainwaring y Scully, se introducen los datos de Latinobarómetro disponibles desde 1995, lo que permite medir comparadamente la intensidad de las lealtades partidistas.

Por otra parte, en Venezuela los partidos fueron altamente eficientes en encapsular los intereses organizados, lo que Mainwaring y Scully consideraban saludable y sintomático de la institucionalización del sistema partidista. No obstante, en el largo plazo, este monopolio representativo contribuyó a la imagen negativa de una partidocracia donde las fuerzas partidistas controlaban de forma excluyente la representación. $\mathrm{Al}$ respecto, Cavarozzi y Garretón (1989) advertían que una de las condiciones para la consolidación de los sistemas partidista era que los partidos no monopolizaran la representación de las demandas e intereses de la

28 Si bien esta encuesta comenzó a ser aplicada en 1988, lo fue con carácter experiemental en 4 países, ampliándose recién en 1995 a 8, llegando finalmente a dar cobertura a 18 países de la región. sociedad civil. Mainwaring y Scully no prestaron atención a este punto.

Una tercera condición o criterio de institucionalización sugiere que los partidos y las elecciones sean aceptados ampliamente como el único medio que determina quien accede al poder. En 1992, la intentona golpista dirigida por Hugo Chávez fue avalada por distintos actores políticos y sectores de la socie$\mathrm{dad}^{29}$, a lo que debe añadirse el crecimiento exponencial del abstencionismo electoral. Si bien las elecciones continuaron siendo el medio para acceder al poder y escoger al personal político, los partidos perdieron la capacidad de seleccionar candidatos y controlar el proceso de competencia electoral, dando paso a candidatos independientes y caudillos que empleaban las etiquetas partidarias de forma contingente.

Finalmente, en relación con el último criterio de Mainwaring y Scully, la fortaleza de las organizaciones partidarias se debilitó notablemente a comienzos de los años noventa. Lo altos niveles de faccionalización, producto de crecientes tensiones entre el nivel central y los caudillos regionales emergentes, provocaron múltiples rupturas y finalmente, la fragmentación de los partidos tradicionales y del sistema en su conjunto. Ahora, es preciso reconocer que el caudillismo comenzó a manifestarse al interior de los partidos tradicionales bajo los liderazgos de Carlos Andrés Pérez y Rafael Caldera,

29 Sobre ese punto es ilustrativa la actitud de apoyo del mismo Rafael Caldera. 
quienes cultivaron un estilo personalista que también habría contribuido a la descomposición del sistema.

\section{IV.CONSIDERACIONES FINALES}

Desde la perspectiva de la institucionalización del sistema de partidos, el caso venezolano presenta una paradoja: un sistema altamente institucionalizado que colapsó dramáticamente a fines de los años noventa. Como concluye el artículo, no hay tal paradoja, sino una limitación en el enfoque que impide captar adecuadamente cierto tipo de cambio a nivel sistémico. La transformación del sistema de partidos se gestó subterráneamente para la contemplación comparada. La descomposición del sistema partidista se incubó en el marco de un sistema de partidos hiperinstitucionalizado, caracterizado por bajos niveles de incertidumbre (alternancia pendular); ciudadanos indiferentes (abstencionismo y bajo interés político); un mercado político cerrado (monopolio electoral bipartidista y control absoluto de la selección de candidatos), baja credibilidad de los liderazgos partidistas y un antipartidismo latente.

La petrificación del sistema partidista y del liderazgo político derivó en un fuerte desajuste o desfase entre la ciudadanía y el liderazgo político. La baja capacidad adaptativa de los partidos terminó con su reemplazo por nuevos actores, lo que se vio catalizado por las reformas en el diseño electoral que redujeron el control de las cúpulas partidistas. El desplome del sistema de partidos puede entenderse como un proceso de largo plazo, en el que se fue erosionando la legitimidad y representatividad del sistema. Los factores identificados fueron agrupados en dos explicaciones alternativas. Por un lado, el predominio excesivo de un grupo reducido de partidos clausuró los espacios de representación. Como se señaló, este monopolio representativo se sostenía cada vez menos en plataformas ideológicas o programáticas y más en intercambios de corte clientelar sustentados en la renta petrolera. Los partidos se fueron convirtiendo en meras correas transmisoras, lo que habría deteriorado la calidad de la representación política.

En el desarrollo del estudio se argumentó que la perspectiva de la institucionalización no detectó a tiempo el desgaste y la descomposición del sistema de partidos. Al respecto, caben varias lecciones para el estudio de los sistemas de partidos aparentemente fuertes y estables. Primero, ilustra que la estabilidad electoral, la baja fragmentación, la persistencia de las etiquetas partidarias y la fortaleza de las organizaciones partidistas pueden coexistir con niveles crecientes de desafección política, abstencionismo, decadencia de la identificación partidaria y la confianza, antipartidismo (reactivo o sistémico) y un extendido malestar hacia el esquema de representación partidista.

En segundo lugar, el caso venezolano entrega pistas para el estudio de otros sistemas de partidos donde los indicadores convencionales arrojan altos 
Andrés DockendorfF • El espejismo de la institución...

niveles de institucionalización. En estos casos, el continuo entre sistema de partidos institucionalizados y fluidos requiere ser extendido hasta los sistemas de partidos hiperinstitucionalizados. Estos producen dinámicas sistémicas (patrones de interacción en la competencia entre partidos) que exceden el continuo y los criterios empleados por el enfoque de la institucionalización. En esa línea, por ejemplo, altos niveles de estabilidad electoral podrían anclarse no tanto en la capacidad adaptativa y la competitividad de los partidos que componen el sistema, sino en la existencia de un mercado político clausurado y una institucionalidad electoral que fabrica estabilidad y facilita el predominio de los viejos partidos.

En el caso chileno, por ejemplo, el sistema de partidos de la democracia restaurada presenta algunas contradicciones similares a las detectadas en la evolución del sistema partidista venezolano. La notable estabilidad electoral y continuidad de las etiquetas partidarias coexiste con niveles decrecientes de identificación partidaria, baja confianza en los partidos, petrificación del padrón electoral y un desencanto general con la política. El viejo electorado sigue siendo estable al votar por partidos y coaliciones, a pesar de que- paradojalmente- no se reconoce identificado o cercano con esos partidos en las encuestas (López, 2008). Esta alta institucionalización partidista y estabilidad electoral no se explicaría en función de la estrecha relación entre partidos y sociedad civil, sino más bien debido a los resultados artefactuales producidos por la institucionalidad electoral (Luna, 2008).

En forma análoga al caso venezolano, este desfase entre la sociedad y el sistema de partidos en Chile se manifiesta en una creciente desafección política y electoral que no ha llegado a niveles dramáticos gracias al corsé institucional proporcionado por el régimen electoral. También se han propuesto reformas al sistema electoral y al régimen de inscripción y sufragio. En Venezuela, las reformas contribuyeron al colapso del sistema partidista. Ello, debido a que dislocaron severamente el eje que soportaba la enorme brecha entre el sistema partidista y la ciudadanía, y que paralelamente contribuía a producir el espejismo de la institucionalización.

De lo anteriormente expuesto, surge la necesidad de que la agenda comparada se oriente también a la comprar los casos catalogados como altamente institucionalizados con el sistema partidista venezolano que colapsó en los años noventa, incluyendo en el continuo, el análisis de la hiperinstitucionalización y sus consecuencias comparativas. A la luz de ese contraste, la imagen robusta que proyectan algunos sistemas partidistas de la región podría verse seriamente discutida.

\section{Bibliografía}

Alcántara, Manuel (2004) «Partidos políticos en América Latina. Precisiones conceptuales, estado actual y retos futuros", documentos CIDOB, $\mathrm{N}^{\circ} 3$, disponible en http://www.cidob.org. 
Alexander, Robert J. (1965), «Democratic Revolution in Venezuela", Annals of the American Academy of Political and Social Science 358: 150-158.

Bordi, Luciano y Peter Mair (2008), «The parameters of party systems", Party Politics 14 (2): 147-166.

Brandler, Natalia (2006), «La abstención en Venezuela; ¿Desafección o protesta democrática?», Politeia 37: 89- 22.

Brewer, Allan (2008), «Reforma electoral en el sistema político en Venezuela", en Zovatto, D y J Orozco (coords.) Reforma política y electoral en América Latina: 1978- 2007. Universidad Nacional Autónoma de México- Institute for Democracy and Electoral Assistance (IDEA). Texto disponible en www.idea.int.

Cavarozzi, Marcelo y Manuel A. Garretón, (coords) (1989), Muerte y resurrección. Los partidos politicos en el autoritarismo y las transiciones del Cono Sur, Santiago de Chile, FLACSO.

Cavarozzi, Marcelo y Esperanza Casullo (2002), «Los partidos políticos en América Latina hoy; ¿consolidación o crisis?», en; Cavarrozi, M. y M. Medina (comps); El asedio a la política: los partidos latinoamericanos en la era neoliberal. Rosario, Argentina, Homo Sapiens- Konrad Adenauer.

Chasquetti, Daniel (2001), «Democracia, multipartidismo y coaliciones en América Latina: evaluando la difícil combinación", en Lanzaro, J (ed.), Tipos de presidencialismo y coaliciones políticas en América Latina, Buenos Aires, CLACSO.

Coppedge, Michael (1993), «Parties and Society in Mexico and Venezuela: Why competition matters", Comparative Politics 25 (3): 253-274.

Coppedge, Michael (1997), «A classification of Latin American political parties». Working Paper 244, Kellog Institute, University of Notre Dame, http/: www.nd.edu.

Coppedge, Michael (1998), «The dynamic diversity of Latin American Party Systems», Party Politics 4 (4): 547-568.

Coppedge, Michael (2000), «Latin American Parties: Political Darwinism in the Lost
Decade». Disponible en http://www. nd.edu/ mcoppedg/crd/ifdssept.htm

Corrales, Javier (2001), «Strong Societies, Weak Parties: Regime Change in Cuba and Venezuela in the 1950s and Today», Latin American Politics and Society 43 (2): 81-113.

Del Campo, Esther y María Ramos (1997), «La paradoja partidista: Institucionalización y representación en los partidos políticos latinoamericanos" América Latina Hoy 16: 29-40.

Di Tella, Torcuato (1997), Historia de los partidos politicos en América Latina, siglo XX, México, D.F., Fondo de Cultura Económico.

DIX, Robert (1989), «Cleavage Structures and Party Systems in Latin America", Comparative Politics 22 (1): 23-37.

Ellner, Steve (1996) «Political party factionalism and democracy in Venezuela", Latin American Perspectives 23 (3): 87-109.

Fernández, Mario (1998), «El voto obligatorio en América Latina", en Nohlen, D, S. Picado y D. Zovatto (comps) Tratado de derecho electoral comparado en América Latina. IIDH-CAPEL, Universidad de Heildelberg, Tribunal Electoral del Poder Judicial de la Federación de México, Instituto Federal Electoral de México, México Fondo de Cultura Económica.

Hartlyn, Jonathan (1998), «Democracies in Contemporary South America. Convergences and diversities», en Tulchin, J y A. Garland (eds); Argentina: The Challenges of Modernization, Willmington, Scholary Resources, Inc.

Huntington, Samuel (1990) [1968], El orden político en las sociedades en cambio, Buenos Aires, Paidós.

Jones, Mark (2007), «Political parties and party systems in Latin America». Trabajo preparado para el Simposio «Prospects for Democracy in Latin America», Departamento de Ciencia Politica, North Texas, Denton, Texas, 5-7 abril.

Karl, Terry (1987), «Petroleum and political pacts: the transition to democracy in Venezuela", Latin American Research Review 22 (1): 63-94. 
Andrés DockendorfF • El espejismo de la institución...

Keoneke, Robert (2000), «Participación política y social en la Venezuela finisecular: factores político-institucionales y motivacionales en la participación y en la apatía ciudadana», Cuadernos del Cendes 17 (45): 123-133.

Kitschelt, Herbert (2000), «Linkages between citizens and politicians in democratic polities», Comparative Political Studies 33 (6/7): 845-879.

Kornblith, Miriam (1991), "The politics of Constitution- Making: Constitutions and democracy in Venezuela", Journal of Latin American Studies 23 (1): 61-89.

Kornblith, Miriam (1994), "La crisis del sistema político venezolano", Nueva Sociedad 134: 142-157.

Kornblith, Miriam (1997), «Crisis y transformación del sistema político venezolano: nuevas y viejas reglas del juego". Trabajo presentado en el XX International Congress of Latin American Studies Association (LASA). Guadalajara, México. Abril 17-19.

Kornblith, Miriam (2003), «Del puntofijismo a la Quinta República: Elecciones y democracia en Venezuela", Colombia Internacional 58 (2): 160-194.

Kornblith, Miriam y Daniel Levine (1993), "Venezuela: The life and time of the party system». Working Paper 197. Disponible en: www.nd.edu/ kellogg/publications/ workingpapers/WPS/197.pdf.

Laakso, M y R. Taagepera (1979), «Effective Number of Parties: A measure with application to West Europe», Comparative Political Studies 12 (1): 3-28.

Lalander, Richard (2004), "La descentralización venezolana y el chavismo: Transformaciones del sistema político partidista», Revista Venezolana de Ciencia Política 26 (2): 29-74.

Lander, Edgard y Luis Fierro (1996), «The impact of neoliberal adjustment in Venezuela, 1989- 1993", Latin American Perspectives 23 (3): 50-73.

Levine, Daniel y Brian Crisp (1999), «Venezuela: Características, crisis y posible futuro democrático", América Latina Hoy 21: 5-24.
Levitsky, Steven y Maxwell Cameron (2003), «Democracy without parties? Political parties and regime change in Fujimori's Peru", Latin American Politics and Society 45 (3): 1-33.

López, Miguel Ángel (2008), «Conducta electoral en Chile: la paradoja de la estabilidad», trabajo elaborado para el IV Congreso Latinoamericano de Ciencia Política (ALACIP), San José de Costa Rica, 5-7 agosto.

Lucena, Tibisay (2003), "Las reformas del sistema electoral venezolano y sus consecuencias políticas: 1988 - 1998", ALCEU 6 (1): 245-265.

Luna, Juan Pablo (2007), «Representación política en América Latina: el estado de la cuestión y una propuesta de agenda", Política y Gobierno XIV (2): 391-435.

Luna, Juan Pablo (2008), «Partidos Políticos y Sociedad en Chile. Trayectoria Histórica y Mutaciones Recientes» en Fontaine, A; C. Larroulet, J. Navarrete e I. Walker (eds.) Reforma de los Partidos Políticos en Chile, PNUD-CEP-LyD-ProyectAmerica- CIEPLAN.

Mainwaring, Scott (1999), «La durabilidad de la democracia en América Latina", Política y Gobierno VI (2): 315- 363.

Mainwaring, Scott y Timothy Scully (1995), La construcción de las instituciones democráticas. Sistemas de partidos en América Latina, Santiago, CIEPLAN.

Mainwaring, Scott y Mariano Torcal (2005), «La institucionalización de los sistemas de partidos y la teoría del sistema partidista después de la tercera ola democratizadora», América Latina Hoy 41: 141: 173.

Mainwaring, Scott y Edurne Zoco (2007), «Political sequences and stabilization of interparty competition", Party Politics 13 (2): 155-178.

Mainwaring, Scott y Timothy Scully (2008), «Latin America: Eight Lessons for Governance», Journal of Democracy 19 (3): 113-127.

Mainwaring, Scott, Annabella España y Carlos Gervasoni (2009), «Extra system electoral volatility and the vote share of Young parties». Trabajo preparado para 
la Reunión Anual de la Asociación Canadiense de Ciencia Política, 28 de mayo.

Malamud, Andrés (2003), «Partidos políticos», en Pinto, J. (comp.) Introducción a la Ciencia Política, Buenos Aires, Eudeba.

Markowski, Radoslaw (2000), «Party System Institutionalization in New Democracies: Poland- a Trend Setter with no followers». Trabajo elaborado para la conferencia «Re- thinking Democracy in the New Millennium», organizada por la Universidad de Houston, 16 -19 de febrero.

Martz, John (1992), «Party Elites and leadership in Colombia and Venezuela", Journal of Latin America Studies 24 (1): 87- 121.

McCoy, Jennifer y William Smith (1995), «Desconsolidación o reequilibrio democrático en Venezuela», Nueva Sociedad 140: 18-32.

Méndez, Ana y Elda Morales (2001), «La democracia venezolana desde el discurso político de los líderes tradicionales", Utopia y Praxis Latinoamericana 6 (14): 9-39.

Merenco, André (2009), "Reformas electorales en América Latina. Condiciones y resultados de los cambios en las reglas de competencia», en Fontaine, A, C. Larroulet, J. Navarrete e I. Walker (Edts); Reforma del Sistema Electoral Chileno. CEP-Libertad y Desarrollo-ProyectAmerica-CIEPLAN: Santiago.

Molina, José (2009), «La reforma informal del sistema electoral venezolano: De la representación proporcional al sistema mayoritario sin alterar una coma», en: Fontaine, A, C. Larroulet, J. Navarrete e I. Walker (eds.) Reforma del Sistema Electoral Chileno, CEP-Libertad y Desarrollo- ProyectAmerica-CIEPLAN

Molina, José (2001), «El sistema de partidos venezolano: de la partidocracia al personalismo y la inestabilidad. La desinstitucionalización y sus consecuencias». Ponencia disponible en: www.lasa.international. pitt.edu/Lasa2001/MolinaJose.pdf

Molina, José y Carmen Pérez (1998ª), «Luces y sombras de la democracia venezolana. A 40 años del 23 de enero", Nueva Sociedad 154 (2): 34- 41.
Molina, José y Carmen Pérez (1998b), «Evolution of the party system in Venezuela, 1946- 1993», Journal of Interamerican Studies and World Affairs 40 (2): 1-26.

Montero, José Ramón; Richard Gunther y Mariano Torcal (1998), «Actitudes hacia la democracia en España: legitimidad, descontento y desafección", Revista Española de Investigaciones Sociológicas 83 (3): 9-49.

Montilla, Luis Enrique (2001), «La abstención electoral en Venezuela y su explicación como factor político, 1958-1998». Revista Venezolana de Ciencia Politica 20: 67-96.

Morgan, Jana (2007), «Partisanship during the collapse of Venezuelan's Party System», Latin American Research Review 42 (1): 78-98.

Morgenstern, Scott (2001), «Grupos organizados y partidos desorganizados. Incentivos electorales en Uruguay», América Latina Hoy 109: 109- 131.

Nohlen, Dieter (1992), «Sistemas electorales y gobernabilidad», Working Paper $\mathrm{N}^{\circ}$ 63, Barcelona, Institut de Ciencies Politiques i Socials.

Nohlen, Dieter (1995), Sistemas electorales y partidos políticos, México, Fondo de Cultura Económica.

Paravisini, Daniel (1998), «Efectos de las reformas sobre el parlamento venezolano: especialización y representación de intereses regionales». Ponencia presentada en el XXI Congreso Internacional de la Latin American Studies Association (LASA), 24- 26 de septiembre, Chicago, Illinois.

Payne, Mark; Daniel Zovatto y Mercedes Mateo (eds) (2006), La política importa. Desarrollo y democracia en América Latina, Washington D.C., Banco Interamericano de Desarrollo.

Pedersen, Mogens (1979), «The dynamics of European Party Systems: Changing Patterns of Electoral volatility», European Journal of Political Research 7 (1): 1-26.

Pereira, Valia (2002), «Fortalezas y debilidades de la actitud democrática en Venezuela», América Latina Hoy 32: 117-131.

Pérez, Carmen (2003), «¿Por qué ganó Hugo Chávez? Tendencias en el comportamien- 
Andrés DockendorfF • El espejismo de la institución...

to electoral venezolano", ALCEU 3 (6): 237-244.

Prud' Homme, Jean François (2001), «Un concepto evasivo: el populismo en la Ciencia Política», en Hermet, G; S. Loaeza y J Prud' Homme (comps), Del populismo de los antiguos al populismo de los modernos, México, El Colegio de México, Centro de Estudios Internacionales.

Rámirez Roa, Rosaly (2003), «La política extraviada en la Venezuela de los años 90: entre rigidez institucional y neo- populismo", Revista de Ciencia Política XXIII (1): 137-158.

Ramos, Alfredo (1999), «Venezuela: el ocaso de una democracia bipartidista", Nueva Sociedad 161: 35-43.

Randall, Vichy y Lars Svassand (1999), «Party Institutionalization and the new Democracies", trabajo elaborado para el ECPR Joint Session of Workshops, Mannheim, 26-31 de marzo.

Rivas Leone, José (2002), «Transformaciones y crisis de los partidos politicos. La nueva configuración del sistema de partidos en Venezuela». Documento de Trabajo 202, Institut de Ciencies Politiques i Socials, Barcelona.

Rivas Leone, José (2006), "Crisis y desinstitucionalización de los partidos políticos en Venezuela", Stockholm Review of Latin American Studies 1: 47-58.

Roberts, Kenneth (2001), «La descomposición del sistema de partidos venezolano vista desde un análisis comparativo", Revista Venezolana de Economía y Ciencias Sociales 7 (2): 183-200.

Roberts, Kenneth (2003), «Social Correlates of Party System Demise and Populist Resurgence in Venezuela», Latin American Politics and Society 45 (3): 35-57.

Roberts, Kenneth y Erik Wibbels (1999), «Party Systems and Electoral volatility in Latin America: a test of economic, institutional and structural explanations", American Political Science Review 93 (3): 575-590.

Rodríguez, Cecilia (2007), «La institucionalización de los sistemas de partidos en América Latina: factores condicionantes».
Ponencia presentada en el VIII Congreso Español de Ciencia Política y Administración Pública. Disponible en http://www. aecpa.es/congreso_08/archivos/area4/GT12/RODRIGUEZ-CECILIA.pdf.

Salamanca, Luis (1994), "Venezuela: la crisis del rentismo", Nueva Sociedad 131 (mayo- junio): 10-19.

Schedler, Andreas (1995), «Under- and OverInstitucionalization: Some Ideal Typical propositions concerning new and old party system». Working Paper 213. Kellogg Institute.

Shugart, Mathew (1992), "Leaders, rank and file and constituents. Electoral reform in Colombia and Venezuela", Electoral Studies 11 (1): 21-45.

Smith, Peter (2004), "Los ciclos de la democracia electoral», Política y Gobierno XI (2): 189-228.

Stein, Ernesto y Mariano Tommasi (2006), "La política de las políticas públicas». Política y Gobierno 13 (2): 393-416.

Stein, Ernesto (ed), (2006), La Política de las Políticas Públicas: Progreso Económico y Social en América Latina, Washington, BID.

Torcal, Mariano (2003), «Political disaffection and democratization history in new democracies». Working Paper 308, Kellogg Institute, Notre Dame University. Disponible en www.nd.edu/ kellogg/publications/ workingpapers/WPS/308.pdf.

Torcal, Mariano, José Montero y Richard Gunther (2007), «Los sentimientos antipartidistas en el sur de Europa», en Montero, J. R. Gunther y J. Linz (eds). Partidos políticos, Viejos conceptos y nuevos retos, Madrid, Editorial Trotta.

Vivas, Abdón (2008), «El proceso de transformación del sistema político de Venezuela (1959-2004)». Tesis Doctoral, Universidad Complutense de Madrid, Departamento de Ciencia Política y Administración III.

Wills, Laura y Aníbal Pérez Liñan (2005), «La evolución de los sistemas electorales en América: 1900-2004», Colección 16: 47-82. 